\title{
Specific-detection of clinical samples, systematic functional investigations, and transcriptome analysis reveals that splice variant MUC4/Y contributes to the malignant progression of pancreatic cancer by triggering malignancy- related positive feedback loops signaling
}

Yi Zhu ${ }^{1,2+}$, Jing-Jing Zhang ${ }^{1,2+}$, Kun-Ling Xie ${ }^{1+}$, Jie Tang ${ }^{1}$, Wen-Biao Liang ${ }^{3}$, Rong Zhu ${ }^{4}$, Yan Zhu ${ }^{5}$, Bin Wang ${ }^{6}$, Jin-Qiu Tao ${ }^{1}$, Xiao-Fei Zhi ${ }^{1}$, Zheng Li ${ }^{1}$, Wen-Tao Gao ${ }^{1,2}$, Kui-Rong Jiang ${ }^{1,2}$, Yi Miao ${ }^{1,2^{*}}$ and Ze-Kuan Xu ${ }^{1,2^{*}}$

\begin{abstract}
Background: MUC4 plays important roles in the malignant progression of human pancreatic cancer. But the huge length of MUC4 gene fragment restricts its functional and mechanism research. As one of its splice variants, MUC4/ $Y$ with coding sequence is most similar to that of the full-length MUC4 (FL-MUC4), together with alternative splicing of the MUC4 transcript has been observed in pancreatic carcinomas but not in normal pancreas. So we speculated that MUC4/Y might be involved in malignant progression similarly to FL-MUC4, and as a research model of MUC4 in pancreatic cancer. The conjecture was confirmed in the present study.

Methods: MUC4/Y expression was detected by real-time quantitative reverse transcription polymerase chain reaction (qRT-PCR) using gene-specific probe in the clinic samples. The effects of MUC4/Y were observed by serial in vitro and in vivo experiments based on stable over-expressed cell model. The underlying mechanisms were investigated by sequence-based transcriptome analysis and verified by qRT-PCR, Western blot and enzyme-linked immunosorbent assays.
\end{abstract}

Results: The detection of clinical samples indicates that MUC4/Y is significantly positive-correlated with tumor invasion and distant metastases. Based on stable forced-expressed pancreatic cancer PANC-1 cell model, functional studies show that MUC4/Y enhances malignant activity in vitro and in vivo, including proliferation under low-nutritional-pressure, resistance to apoptosis, motility, invasiveness, angiogenesis, and distant metastasis. Mechanism studies indicate the novel finding that MUC4/Y triggers malignancy-related positive feedback loops for concomitantly up-regulating the expression of survival factors to resist adverse microenvironment and increasing the expression of an array of cytokines and adhesion molecules to affect the tumor milieu. (Continued on next page)

\footnotetext{
*Correspondence: miaoyi@njmu.edu.cn; xuzekuan@njmu.edu.cn

${ }^{\dagger}$ Equal contributors

${ }^{1}$ Department of General Surgery, First Affiliated Hospital, Nanjing Medical University, 300 Guangzhou Road, Nanjing 210029, Jiangsu Province, People's Republic of China

${ }^{2}$ Jiangsu Province Academy of Clinical Medicine, Institute of Tumor Biology,

Nanjing 210029, People's Republic of China

Full list of author information is available at the end of the article
} 
(Continued from previous page)

Conclusions: In light of the enormity of the potential regulatory circuitry in cancer afforded by MUC4 and/or MUC4/ Y, repressing MUC4 transcription, inhibiting post-transcriptional regulation, including alternative splicing, or blocking various pathways simultaneously may be helpful for controlling malignant progression. MUC4/Y- expression model is proven to a valuable tool for the further dissection of MUC4-mediated functions and mechanisms.

Keywords: MUC4/Y, Alternative splicing, Pancreatic neoplasms, Cell movement, Angiogenesis, Neoplasm metastasis, Gene expression regulation, Signal transduction

\section{Background}

Mucins are a family of high-molecular weight glycoproteins implicated in diverse biological function [1]. A member of the transmembrane mucin family [2,3], mucin 4 (MUC4) has been mapped to chromosome 3 in the q29 region, which was cloned from the human tracheobronchial chromosomal DNA library and a human pancreatic tumor cell line [2-5]. MUC4 plays important roles in the carcinogenesis and progression of multiple human cancers, including pancreatic cancer [6,7]. MUC4 is aberrantly expressed in pancreatic ductal adenocarcinoma (PDAC) and precancerous pancreatic intraepithelial neoplasias, but not in benign or normal parts of the pancreas [8-10], and the level of expression correlates significantly with poor prognosis of PDAC $[10,11]$. But because of the huge length of its gene fragment (more than $30 \mathrm{~KB}$ ), it is incapable to clone and eukaryotic express the full-length MUC4 gene. The function predictions and structure analyses of human MUC4 were mostly from the overexpression of its rat homologous gene rMuc4/SMC on human tumor cells.

We have noticed that alternative splicing of the MUC4 transcript has been observed in pancreatic carcinomas but not in normal pancreas [12-14]. MUC4 has a series of splice variants (SV), including an SV1-21 isoform termed SV0 (the full-length MUC4 [FL-MUC4]), MUC4/X, and MUC4/Y. MUC4/Y has the coding sequence most similar to that of FL-MUC4 [15]. Though it lacks the coding exon 2, MUC4/Y has the same exon sequences as FL-MUC4, and the encoded protein has the same conserved domains and a transmembrane $\beta$-subunit that contains three epidermal growth factor (EGF) domains, a transmembrane sequence, a short cytoplasmic tail, and multiple $N$-glycosylation sites as those in FL-MUC4. So we speculated that MUC4/Y may be involved in carcinogenesis and progression similarly to FL-MUC4. More importantly, it may be as a research function model of MUC4 in pancreatic cancer. Furthermore, based on $\mathrm{MUC4} / \mathrm{Y}$, it is easy to construct the unique domainlacking models of MUC4 for its structure analyses and mechanisms dissection.

Thus, the present study aimed to illustrate the role of MUC4/Y in the progression of pancreatic cancer and give insights into its downstream signaling effects: 1)
Quantitatively assess MUC4/Y expression in tissue samples from PDAC patients using probe-specific primers were done to illustrate the correlation of $\mathrm{MUC4} / \mathrm{Y}$ expression with clinicopathological factors and PDAC patient survival. 2)Various in vitro and in vivo assays were conducted using stable MUC4/Y-overexpressing pancreatic cancer cell models to illustrate its function in promoting the malignant properties of pancreatic cancer. 3) The underlying molecular mechanisms were investigated by sequence-based digital gene expression (DGE) analysis and bioinformatics analyses to provide full explanations.

\section{Methods}

\section{Selection of patients and tissue specimens}

We enrolled 108 patients for this retrospective study. The patients had undergone pancreaticoduodenectomy (Whipple resection) with histologically proven PDAC at the Department of General Surgery of the First Affiliated Hospital of Nanjing Medical University between 2006 and 2012. The Ethics Committee of the First Affiliated Hospital of Nanjing Medical University (Permit Number: 2009-SR-031) approved this study. Each patient provided informed consent.

The patients (61 men and 47 women; age range: $25-82$ years; mean age: $60.98 \pm 11.39$ years) were regularly followed until May 31, 2013. Overall survival (OS) was defined as the time between surgery and death or the last follow-up date. No patient died within one month after surgery. Additional file 1: Table S1 summarizes the corresponding characteristics of the patients; staging and grading were based on the sixth edition of the American Joint Committee on Cancer guidelines [16].

Tissue samples were removed as soon as possible after resection and divided into at least two bulk tissue samples. A part of each sample was snap-frozen in liquid nitrogen and then stored in liquid nitrogen until used for RNA extraction. The remainder was fixed in formalin, embedded in paraffin, and cut into 4- $\mu \mathrm{m}$ thick sections for hematoxylin-eosin (H\&E) staining. All tissue samples were examined histologically; experienced pathologists confirmed the diagnosis. Histological grades of tumor differentiation were assigned according to World Health Organization criteria. 
RNA extraction and quantitative assessment of MUC4/Y and MUC4 by real-time reverse transcription-PCR with specific primers

Following liquid nitrogen grinding, total RNA was extracted from bulk tissues with TRIzol (Life Technologies) according to the manufacturer's protocol. After spectrophotometry quantification, $1 \mu \mathrm{g}$ total RNA was used in a final volume of $20 \mu \mathrm{L}$ for reverse transcription (RT) with an iScript cDNA Synthesis Kit ((Bio-Rad, CA, USA) according to the manufacturer's instructions. Quantitative real-time PCR was performed using TaqMan Gene Expression Assays (Life Technologies) in a StepOnePlus Real-Time PCR System (Life Technologies). Reactions were performed in $10-\mu \mathrm{L}$ volumes containing $1 \mu \mathrm{L}$ diluted complementary DNA (cDNA), 20× TaqMan Gene
Expression Assay Mix, and 2x TaqMan Universal PCR Master Mix. The thermal cycling conditions comprised initial denaturation at $95^{\circ} \mathrm{C}$ for $10 \mathrm{~min}$ and 40 cycles at $95^{\circ} \mathrm{C}$ for $15 \mathrm{~s}$ and $60^{\circ} \mathrm{C}$ for $1 \mathrm{~min}$. The product number of the MUC4 TaqMan Gene Expression Assay Mix was Hs003666414 (Applied Biosystems). Figure 1A depicts the specific primers (forward: 5'-TGGGTGTCCCTGA GCTGC-3', reverse: 5' -TGATGTGGCTGTGCGTCTC$\left.3^{\prime}\right)$ and TaqMan probe (5'-ATGTGGTCCCAGGAATG ACAACACCGT-3') designed for MUC4/Y. In addition to BLASTN searches, we performed RT-PCR with human pancreatic cancer HPAC cell-lines using the MUC4/Y forward and reverse primers, and the target PCR product was subcloned into a pMD18-T vector for DNA sequencing to ensure the specificity of each primer and confirm

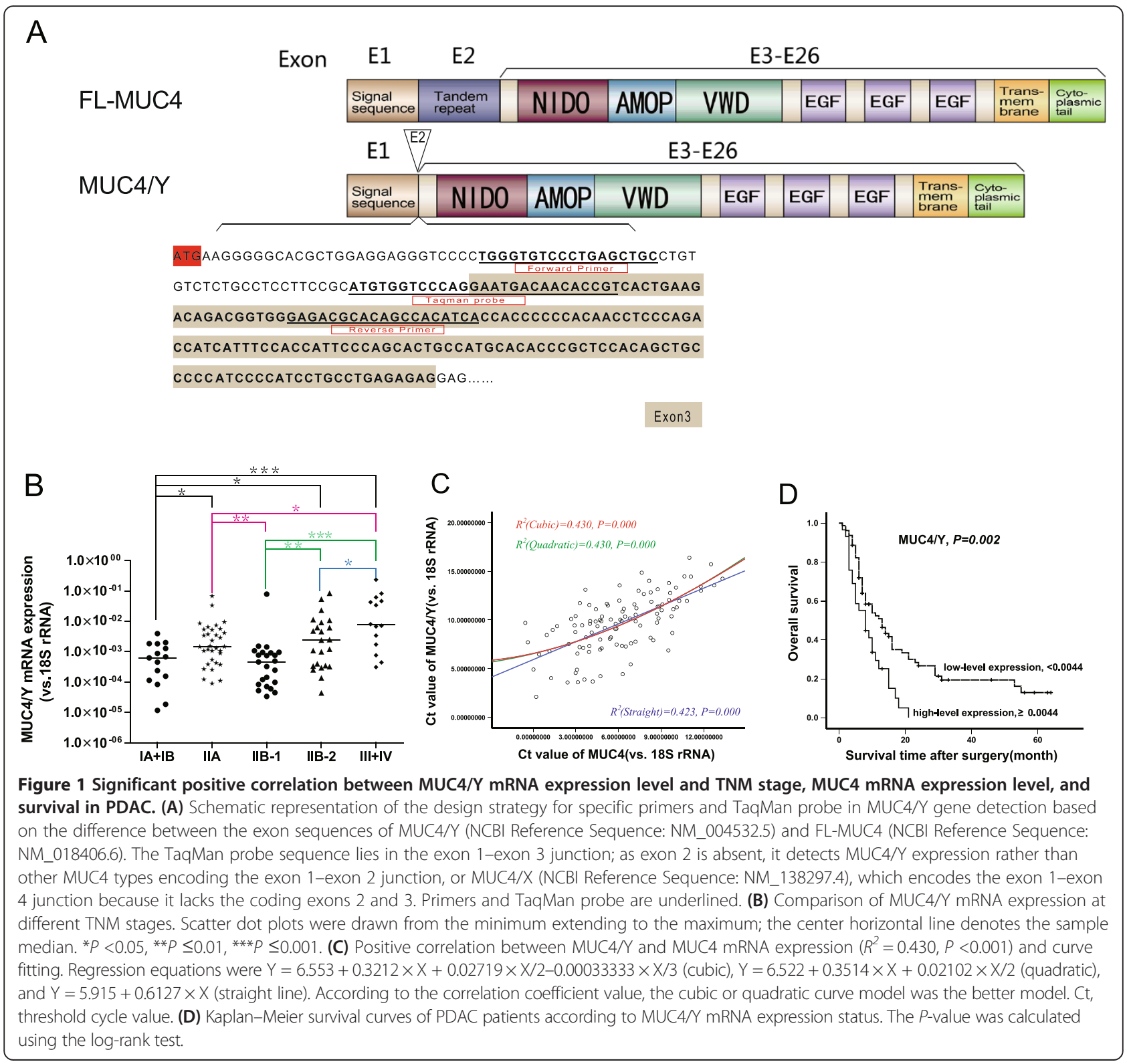


that the sequence was correct. Human 18S rRNA (Hs099999901_s1; Applied Biosystems) was used as the internal control for each sample to calibrate the original concentration of mRNA [17]. Relative gene expression was calculated by subtracting the threshold cycle $(\mathrm{Ct})$ value of the target genes and 18S rRNA (control) genes using the $2^{-\Delta C t}$ method [18]. Each quantification PCR was performed in triplicate and repeated thrice independently.

\section{Cell culture and stable overexpression of MUC4/Y}

The PANC-1 pancreatic cancer cell line was obtained from the Shanghai Institutes for Biological Sciences, Chinese Academy of Sciences, and grown in Dulbecco's modified Eagle's medium (DMEM) containing high glucose (Wisent Biocenter, Canada) and supplemented with $10 \%(\mathrm{v} / \mathrm{v})$ fetal bovine serum (FBS; Wisent Biocenter, Canada) and penicillin-streptomycin (HyClone, Thermo, USA) at $37^{\circ} \mathrm{C}$ in a humidified atmosphere containing $5 \% \mathrm{CO}_{2}$.

We designed full-length cDNA fragments encoding the MUC4/Y gene, i.e., human MUC4 cell surface-associated transcript variant 4 (NCBI Reference Sequence: NM_004 532.5, GI:336285420) containing a Kozak sequence (GCCACC) before the ATG initiation codon for optimal translation and with unique restriction sites present in the multiple clone site (MCS) of the lentiviral vector but absent from the MUC4/Y cDNA sequence. The target sequence was synthesized and cloned in a pUC57 vector (GenScript). Then, the cDNA encoding MUC4/Y was subcloned into the lentiviral vector PCDH-CMV-MCS-EF1Puro (Cat. \#CD510B-1, System Biosciences, USA). To generate viral particles, $293 \mathrm{~T}$ cells were transiently transfected with $\mathrm{pCDH}-\mathrm{CMV}-\mathrm{MCS}-\mathrm{EF} 1-\mathrm{Puro} / \mathrm{MUC} 4 / \mathrm{Y}$ and the pPACKH1 Lentivector Packaging Kit (Cat. \#LV500A-1, System Biosciences, USA) with Lipofectamine 2000 (Invitrogen Life Technology) according to the manufacturer's instructions. The virus titer was detected with quantitative real-time PCR after concentrating and harvesting the viral supernatant $48 \mathrm{~h}$ after transfection. At $24 \mathrm{~h}$ after plating, stable transduction of PANC-1 cells was carried out at 20 multiplicity of infection with the virus and using polybrene $(8 \mu \mathrm{g} / \mathrm{mL}$; Sigma-Aldrich) to augment infection efficiency. Stable clones were then selected in medium containing puromycin $(2 \mu \mathrm{g} / \mathrm{mL}$; Sigma-Aldrich).

Using real-time PCR, western blotting, and immunofluorescence, we detected the mRNA and protein expression and location of the target genes. Stable transfected PANC-1 cells overexpressing the $M U C 4 / Y$ gene were designated PANC-1-MUC4/Y; PANC-1 cells transfected with empty lentiviral vectors (EV) were designated PANC-1-EV. Wildtype PANC-1 and PANC-1-EV cells were used as blank and negative control groups, respectively. No differences were observed between the PANC-1-EV and wild-type PANC-1 cells.

\section{Western blotting}

PANC-1-derived clones were processed for protein extraction and western blotting using standard procedures. Cell lysates were prepared as described previously [19]. After the concentrations were determined using the Bradford assay, proteins (30 $\mu \mathrm{g} / \mathrm{lane})$ were resolved on $4-20 \%$ Mini-PROTEAN TGX precast gels (\#456-1093; Bio-Rad). The resolved proteins were transferred onto polyvinylidene difluoride membranes, blocked with $5 \%$ non-fat milk in phosphate-buffered saline (PBS) for $2 \mathrm{~h}$, and subjected to standard immunodetection procedures using specific antibodies. The following primary antibodies were used to label the membranes: $1 \mu \mathrm{g} / \mathrm{mL}$ anti-MUC4 mouse monoclonal antibody (ab60720; Abcam, Cambridge, UK) and anti-glyceraldehyde-3-phosphate dehydrogenase (GAPDH) mouse monoclonal antibody (1:1000, AG019; Beyotime, CHINA). The membranes were incubated at $4{ }^{\circ} \mathrm{C}$ overnight, followed by six 10-min washes in TBST [50 mmol/ L Tris- $\mathrm{HCl}$ (pH 7.4), $150 \mathrm{mmol} / \mathrm{L} \mathrm{NaCl}, 0.05 \%$ Tween 20], and were incubated with horseradish peroxidase-labeled goat anti-mouse immunoglobulin G (IgG, 1:2000; \#A0216; Beyotime) for $1 \mathrm{~h}$ at room temperature, followed by six 10min washes with TBST. The blots were developed with an enhanced chemiluminescence kit (Amersham, Freiburg, Germany). The internal molecular weight standard was PageRuler Plus Prestained Protein Ladder (\#26619/ SM1811, 10-250 kD; Fermentas).

\section{Immunofluorescence}

Cells cultured to $70 \%$ confluence were washed with $0.1 \mathrm{~mol} / \mathrm{L}$ HEPES containing Hanks' buffer and fixed with Immunol Staining Fix Solution (\#P0098; Beyotime) at room temperature for $15 \mathrm{~min}$. After three 10-min washes in Immunol Staining Wash Buffer (\#P0106; Beyotime), the fixed cells were blocked in Immunol Staining Blocking Buffer (\#P0102; Beyotime) for $60 \mathrm{~min}$ at room temperature for nonspecific blocking, followed by incubation at $4^{\circ} \mathrm{C}$ overnight with anti-MUC4 mouse monoclonal antibody (1:100 in PBS, ab60720; Abcam). Cells were washed 3-5 times for 10 min with PBS containing $0.05 \%$ Tween 20 (PBS-T) and then incubated with cyanine 3labeled goat anti-mouse secondary antibodies (\#P0193; Beyotime) at $37^{\circ} \mathrm{C}$ for $60 \mathrm{~min}$. The cells were washed again 3-5 times for $10 \mathrm{~min}$ with PBS-T. Nuclei were counterstained with diaminophenylindole $(0.5 \mu \mathrm{g} / \mathrm{mL})$ for 5 minutes. Immunostaining was observed under a Nikon Ti-E inverted fluorescence microscope; representative photographs were captured using NIS-Elements D4.0 software (Nikon). 


\section{Cell proliferation assay}

Cell proliferation was determined using Cell Counting Kit-8 (\#C0038; Beyotime) according to the manufacturer's instructions. Briefly, $1 \times 10^{3}$ cells/well were seeded in a 96well flat-bottomed plate and grown at $37^{\circ} \mathrm{C}$ for $24,48,72$, 96, and $120 \mathrm{~h}$. Cells were grown in high- (10\% FBS) or low-serum (1\% FBS) medium. After $10 \mu \mathrm{L}$ WST-8 dye was added to each well, cells were incubated at $37^{\circ} \mathrm{C}$ for $4 \mathrm{~h}$ and the absorbance at $450 \mathrm{~nm}$ determined using a microplate reader.

\section{Apoptosis assay}

Many agents, including the clinically useful sorafenib, can induce apoptosis [20]. Following 24-h treatment with $8 \mu \mathrm{M}$ sorafenib, PANC-1-derived clones were trypsinized, washed with cold PBS, and resuspended in PBS. The advantage of 7-amino-actinomycin D (7-AAD) over propidium iodide is that there is minimal spectral overlap between the emissions. We used a fluorescein isothiocyanate (FITC) Annexin V Apoptosis Detection Kit with 7-AAD (\#640922; BioLegend, USA) according to the manufacturer's instructions. Briefly, $5 \mu \mathrm{L}$ FITCannexin $\mathrm{V}$ and $5 \mu \mathrm{L}$ 7-AAD Viability Staining Solution (\#00-6993; eBioscience, USA) were added to a $100-\mu \mathrm{L}$ cell suspension $\left(1 \times 10^{6}\right.$ cells $)$ in binding buffer. The cells were gently vortexed and incubated for $15 \mathrm{~min}$ at room temperature in the dark, and $400 \mu \mathrm{L}$ binding buffer was added for flow cytometric analysis using a FACScan Flow Cytometer (Becton Dickinson).

\section{Cell migration and invasion assays}

We used modified 24-well Boyden chambers for the cell migration and invasion assays. The top chamber (Transwell) containing a polycarbonate filter membrane $(8-\mu \mathrm{m}$ pore size; BD Labware) was inserted into a 24 -well plate (bottom chamber); a Transwell filter membrane coated with $40 \mu \mathrm{L}$ Matrigel (BD Biosciences) was used in the invasion assay. Medium containing $10 \%$ FBS was placed in the bottom chamber as a chemoattractant. Cells $\left(3 \times 10^{5}\right)$ in $300 \mu \mathrm{L}$ serum-free medium were placed in the top chamber and incubated at $37^{\circ} \mathrm{C}$ for $24 \mathrm{~h}$. Cells that had migrated or invaded through the Matrigel on the bottom surface of the filter were fixed with $4 \%$ paraformaldehyde for $10 \mathrm{~min}$ and stained with $5 \%$ crystal violet (SigmaAldrich) in $25 \%$ methanol for $10 \mathrm{~min}$. Cells on the top surface of the filter (cells that did not migrate or invade through the Matrigel) were removed using a moist cotton swab. Cells in 10 random fields were evaluated under $\times 400$ magnification. The experiments were repeated thrice. Data were expressed as the number of cells per area.

\section{Endotube formation assay}

We measured endotube formation by human umbilical vein endothelial cells (HUVECs) using an angiogenesis assay on Matrigel (Growth Factor Reduced Matrigel Matrix; BD Biosciences). To investigate the influence of MUC4/Y overexpression on PANC-1 cell-HUVEC interaction on HUVEC endotube formation, we co-cultured HUVECs with control and genetically modified PANC-1 cells using a double-chamber method in 24-well tissue culture plates. Stable cell lines $\left(1 \times 10^{5}\right.$ cells) were seeded into Transwell chambers consisting of polycarbonate membranes with 0.4-mm pores (BD Biosciences) and allowed to adhere overnight. To reconstitute the basement membrane, Matrigel was diluted 2-fold with cold DMEM (without FBS) and added to the plates $(250 \mu \mathrm{L} /$ well $)$ at $4^{\circ} \mathrm{C}$. Plates were incubated for $2 \mathrm{~h}$ in a $37^{\circ} \mathrm{C}$ cell culture incubator to allow the Matrigel to solidify. HUVECs were trypsinized, counted, resuspended in basal medium, and added on top of the reconstituted basement membrane $\left(5 \times 10^{4}\right.$ cells/well). The top chamber was then placed in the HUVEC endotube formation assay system on Matrigel as described above. Cells were incubated for $16 \mathrm{~h}$ to allow tube formation. Endotubes were quantified by counting five random fields from each sample under $\times 40$ magnification.

\section{Animals}

Thirty-two female BALB/C nude mice were purchased from the Nanjing University Model Animal Research Center and housed in specific pathogen-free conditions. This study was conducted in strict accordance with the recommendations in the Guide for the Care and Use of Laboratory Animals of the Ministry of Health, China. The Ethics Committee of the First Affiliated Hospital of Nanjing Medical University (Permit Number: 2012-SRFA093) approved the protocol. The mice were randomly assigned to four groups when they were $3-5$ weeks old and weighed 18-20 g: two groups each for subcutaneous and orthotopic models. All surgery was conducted under sodium pentobarbital anesthesia and all efforts were made to minimize suffering.

\section{Subcutaneous model and bioluminescence imaging}

PANC-1-derived clones, i.e., PANC-1-MUC4/Y and PANC-1-EV, were re-transfected with lentivirus (\#pSB72; ShangHai SBO Medical Biotechnology, CHINA) expressing both luciferase and green fluorescent protein (GFP). GFP-expressing cells were sorted using a fluorescenceactivated cell sorter (FACS) and termed PANC-1-MUC4/ Y-Luc and PANC-1-EV-Luc (negative control), respectively. Subconfluent cultures of PANC-1-MUC4/Y-Luc and PANC-1-EV-Luc cells were trypsinized and washed with PBS. Cell viability was determined by trypan blue staining; single-cell suspensions with $>90 \%$ viability were used for the subcutaneous injections. Cells in $100-\mu \mathrm{L}$ suspensions $\left(1 \times 10^{7}\right)$ from each group of cells were injected 
subcutaneously into the flanks of the animals. Beetle luciferin (150 mg/kg in PBS; Promega) was used as the substrate for the luciferase-expressing cells and injected intravenously 1-2 minutes before imaging. Mice were anesthetized using 3.5\% chloral hydrate and imaged at 2 hours and 3, 10, 15, 21, 26, 30 days after tumor cell injection and using a cooled charged-coupled device camera (IVIS system; Xenogen). Exposure times for saturated images were reduced accordingly. Images were quantified as photons/s using Living Image software (Xenogen). In vivo tumor growth was monitored by measuring bioluminescence imaging (BLI). At 30 days after implantation, the mice were sacrificed and the tumors harvested for paraffin embedding and H\&E staining, and immunohistochemical (IHC) analysis.

\section{IHC, Ki67 staining, TUNEL, microvessel density assay}

IHC staining was carried out using the standard avidinbiotin complex method using Ki67 antibody (Dako, MIB-1, 1:200). Immune reactions were visualized with 3,3-diaminobenzidine and counterstained with Mayer's hematoxylin. Ki67-positive cells were counted and presented as the average of the five highest areas within a single $\times 400$ magnification field. Terminal deoxynucleotidyl transferase-mediated dUTP nick end labeling (TUNEL) was carried out using an ApopTag Plus Peroxidase In Situ Apoptosis Detection kit (Intergen) according to the manufacturer's instructions. Briefly, slides were deparaffinized and treated with $20 \mu \mathrm{g} / \mathrm{mL}$ proteinase $\mathrm{K}$ at $37^{\circ} \mathrm{C}$ for $15 \mathrm{~min}$ to enhance staining. After immersion in $3 \%$ hydrogen peroxide to block endogenous peroxidase, slides were incubated with reaction buffer containing terminal deoxynucleotidyl transferase at $37^{\circ} \mathrm{C}$ for $1 \mathrm{~h}$. The slides were then incubated with peroxidase-conjugated anti-digoxigenin antibody for $30 \mathrm{~min}$, and the reaction products were visualized with $0.03 \%$ 3,3-diaminobenzidine containing $2 \mathrm{mmol} / \mathrm{L}$ hydrogen peroxide. TUNEL-positive cells were counted and presented as the average of the five highest areas within a single $\times 200$ field. To determine microvessel density (MVD), 5- $\mu \mathrm{m}$ paraffin-embedded sections were stained with rat anti-mouse CD31 monoclonal antibody (BD Biosciences). The average number of CD31-positive vessels per field, denoting MVD, were examined under $\times 100$ magnification and counted.

\section{Orthotopic model metastasis assay}

Cells $\left(2 \times 10^{6}, 50-\mu \mathrm{L}\right.$ suspensions) from PANC-1-derived cell lines were orthotopically implanted in the pancreas of nude mice as previously described [21]. The mice were sacrificed at 45 days after implantation. The presence of metastatic lesions in other organs was determined by thorough gross inspection and histological analysis.

\section{Sequence-based digital gene expression analysis}

Total RNA was extracted from three groups of cells: PANC-1-MUC4/Y, wild-type PANC-1, and PANC-1-EV using TRIzol (Invitrogen) according to the manufacturer's protocol. RNA integrity was confirmed using a 2100 Bioanalyzer (Agilent Technologies). The samples intended for transcriptome analysis were processed by BGI. Briefly, $6 \mu \mathrm{g}$ total RNA was extracted, the mRNA purified using oligo(dT) magnetic bead adsorption, and cDNA synthesized using oligo $(\mathrm{dT})$ as the primer. The $5^{\prime}$ ends of tags can be generated using two endonucleases: NlaIII or $D p n I I$. Typically, the bead-bound cDNA is digested with NlaIII, which recognizes and cuts off CATG sites. Fragments other than the 3' cDNA fragments connected to the oligo $(\mathrm{dT})$ beads are washed away and Illumina adaptor 1 is ligated to the sticky $5^{\prime}$ end of the digested, beadbound cDNA fragments. The junction of adaptor 1 and a CATG site is the recognition site for $\mathrm{Mmel}$, an endonuclease with separate recognition and digestion sites. It cuts 17 bp downstream of the CATG site, producing tags with adaptor 1 . After removing the 3 ' fragments with magnetic bead precipitation, Illumina adaptor 2 is ligated to the $3^{\prime}$ ends of the tags, producing tags with different adaptors at both ends to form a tag library. Following linear PCR amplification, fragments are purified by polyacrylamide gel electrophoresis. During the quality control steps, the Agilent 2100 Bioanalyzer and Applied Biosystems StepOnePlus Real-Time PCR System are used to quantify and qualify the sample library, which is sequenced using Illumina HiSeq 2000. The raw tag sequence data are analyzed for gene annotation and normalization, screening of differentially expressed genes (DEGs), and functional annotation through the in-house bioinformatics analysis pipeline.

\section{DEG Gene Ontology functional enrichment and pathway enrichment analysis}

DEGs annotated against the Gene Ontology (GO) and Kyoto Encyclopedia of Genes and Genomes (KEGG) databases were enriched to identify significant GO biological process terms and pathways, respectively, and adjusted with corrected $P \leq 0.05$ for $\mathrm{GO}$ analysis and pathways.

\section{Verification of DEGs and VEGF family molecules}

Additional file 1: Table S2 lists the sequences of the specific primer sets. The endogenous control gene (18S rRNA) was used as an internal control. Quantitative RTPCR (qRT-PCR) was performed using a SYBR Premix Ex Taq Kit (TaKaRa) according to the manufacturer's protocol. A no-template control sample (nuclease-free water) was included to detect contamination and to determine the degree of dimer formation. Ct values were normalized to the $18 S$ gene and a relative quantitative method $(\Delta \Delta \mathrm{Ct})$ was used to evaluate quantitative variation. To 
determine biological variability within cell lines, we measured up to three independent RNA samples per line. cDNA was generated using an iScript cDNA Synthesis Kit (Bio-Rad).

Additional file 1: Table S3 lists the sets of specific antibodies and concentration used; we performed Western blotting assays as described above.

To confirm the mechanism of MUC4/Y enhancement of HUVEC endotube formation, we performed enzymelinked immunosorbent assay (ELISA) of vascular endothelial growth factor (VEGF, main detection of VEGFA) and interleukin-8 (IL8) in cell culture supernatants using a kit as per the manufacturer's instructions (R\&D Systems). We collected the supernatant from PANC-1-EV, and PANC-1-MUC4/Y cell cultures. Cells $\left(1 \times 10^{5} / \mathrm{mL}\right)$ were seeded in a 24-well plate and cultured overnight. The medium was replaced and cells were cultured for another $24 \mathrm{~h}$ or $48 \mathrm{~h}$. The culture media were collected and microfuged at $1500 \mathrm{rpm}$ for $5 \mathrm{~min}$ to remove particles, and the supernatant stored at $-80^{\circ} \mathrm{C}$ until used in the ELISA.

\section{Statistical analysis}

Statistical analysis was performed using SPSS 17.0 (SPSS Inc.). The results were confirmed by conducting at least three independent experiments for all in vitro and in vivo experiments.

Data obtained from patients and tissue specimens were analyzed as described previously [10]. Data were analyzed using the Mann-Whitney $U$ test (or Kruskal-Wallis test). All statistical tests were 2-tailed exact tests, with $P<0.05$ considered significant. Based on MUC4/Y expression level cut-off values determined by receiver operating characteristic (ROC) curve analysis, survival distributions were estimated using the Kaplan-Meier method. Variables with statistically significant prognostic value in univariate analyses were entered into a multivariate model and excluded where $P>0.10$. Stepwise selection of factors was applied to the multivariate Cox regression model to identify independent prognostic factors for OS.

Between the two groups in the subcutaneous model, the mean tumor growth rates of Luc-PANC-1 cells at different time points determined by BLI (photons/s) were compared using repeated-measures analysis of variance (ANOVA) to identify subject-by-time profiles.

Between the two groups in the orthotopic model, incidence of metastasis was compared using Fisher's exact test.

All data presented are the mean \pm standard deviation (SD) of $n$ independent measurements unless noted otherwise. Statistical analysis was performed with oneway ANOVA for multiple groups and the unpaired Student $t$-test for individual groups; statistical significance was assigned when $P<0.05$.

\section{Results \\ MUC4/Y mRNA expression was significantly positively correlated with tumor invasion, distant metastases and MUC4 mRNA expression level}

Figure 1 depicts the level of MUC4/Y expression normalized to that of $18 \mathrm{~S}$ rRNA. As shown in Table 1, The Mann-Whitney $U$ test (2-tailed exact tests) demonstrated the level of tumor MUC4/Y expression was significantly correlated with tumor-node-metastasis (TNM) stage $(P=0.001)$, but no significant correlations were identified between the levels of tumor $M U C 4 / Y$ expression and other variables. TNM Staging System for pancreatic cancer were shown in Additional file 1: Table S1. Here Stage IIB can be divided in two groups: one defined as IIB-1, i.e. Tumor limited to the pancreas, Regional lymph node metastasis, No distantant metastasis $(\mathrm{T} 1+\mathrm{T} 2, \mathrm{~N} 1$, M0); the other defined as IIB-2, i.e. Tumor extends beyond pancreas but locally invasive, Regional lymph node metastasis, No distantant metastasis (T3, N1, M0). As shown in Figure 1B, MUC4/Y expression at TNM stage IA + IB was significantly lower than that at TNM stage IIA, IIB-2 or III + IV $(P=0.012,0.022,0.001)$. MUC4/Y expression at TNM stage IIA was significantly lower than that at TNM stage III + IV $(P=0.012)$. MUC4/Y expression at TNM stage IIB-1 was significantly lower than that at TNM stage IIA, IIB-2 or III + IV ( $P=0.004,0.004,0.000)$. MUC4/Y expression at TNM stage IIB-2 was significantly lower than that at TNM stage III + IV $(P=0.047)$. There was no significant difference between MUC4/Y expression at TNM stage IA + IB and IIB- $1(P=0.591)$. There was also no significant difference between MUC4/Y expression at TNM stage IIA and IIB-2 $(P=0.752)$.

We quantified the correlation between MUC4/Y and MUC4 expression levels in pancreatic cancer tissues with real-time PCR. Figure $1 \mathrm{C}$ depicts a positive correlation between MUC4/Y and MUC4 expression levels in $\operatorname{PDAC}\left(R^{2}=0.430, P<0.001\right)$.

\section{Association between MUC4/Y mRNA expression levels, or clinicopathological factors and PDAC patient survival}

We enrolled 108 PDAC patients in the survival analysis. Eighty-four patients died; the remaining 24 patients were alive at the last follow-up (May 31, 2013). The OS rates at 12,18 , and 24 months were $37.96 \%, 21.30 \%$, and $15.74 \%$, respectively. Patients were divided into two groups based on the length of OS: short-term survivors (survival $<24$ months) and long-term survivors (survival $\geq 24$ months).

The threshold value of 0.0044 was chosen as the cutoff score for both high and low MUC4/Y expression, as 0.0044 (within the MUC4/Y expression 95\% confidence interval $[\mathrm{CI}]$ of $0.0043-0.0150$ ) was on the ROC curve closest to $(0.0,1.0)$. This maximized both sensitivity and 
Table 1 Clinicopathological factors and the expression of MUC4/Y in 108 patients with PDAC

\begin{tabular}{|c|c|c|c|c|}
\hline \multirow[t]{2}{*}{ Category } & \multirow[t]{2}{*}{$N(\%)$} & \multicolumn{3}{|c|}{ MUC4/Y } \\
\hline & & Mean & Median(range) & $P$ Value \\
\hline \multicolumn{5}{|l|}{ Age(y) } \\
\hline$<60$ & $47(43.52)$ & 0.0076 & $0.0010(0.0000-0.0829)$ & 0.689 \\
\hline$\geq 60$ & $61(56.48)$ & 0.0112 & $0.0012(0.0000-0.2350)$ & \\
\hline \multicolumn{5}{|l|}{ Gender } \\
\hline Male & $61(56.48)$ & 0.0117 & $0.0013(0.0000-0.2350)$ & 0.228 \\
\hline Female & $47(43.52)$ & 0.0070 & $0.0010(0.0000-0.0787)$ & \\
\hline \multicolumn{5}{|c|}{ Location of tumor } \\
\hline Head & $72(66.67)$ & 0.0071 & $0.0010(0.0000-0.0842)$ & 0.494 \\
\hline Body and tail & $36(33.33)$ & 0.0147 & $0.0015(0.0000-0.2350)$ & \\
\hline \multicolumn{5}{|l|}{ Size of tumor } \\
\hline$\leq 2 \mathrm{~cm}$ & $22(20.37)$ & 0.0074 & $0.0010(0.0000-0.0682)$ & 0.647 \\
\hline$>2 \mathrm{~cm}$ & $86(79.63)$ & 0.0102 & $0.0011(0.0000-0.2350)$ & \\
\hline \multicolumn{5}{|l|}{ Nerve infiltration } \\
\hline No & $38(35.19)$ & 0.0098 & $0.0007(0.0000-0.0842)$ & 0.137 \\
\hline Yes & $70(64.81)$ & 0.0096 & $0.0012(0.0000-0.2350)$ & \\
\hline \multicolumn{5}{|l|}{ Differentiation } \\
\hline Well & $15(13.89)$ & 0.0267 & $0.0012(0.0000-0.2350)$ & 0.979 \\
\hline Moderate & $83(76.85)$ & 0.0071 & $0.0011(0.0000-0.0842)$ & \\
\hline Poor & $10(9.26)$ & 0.0055 & $0.0011(0.0001-0.0340)$ & \\
\hline \multicolumn{5}{|l|}{ TNM ${ }^{\mathrm{a}}$ staging } \\
\hline$|A+| B$ & $15(13.89)$ & 0.0009 & $0.0006(0.0000-0.0040)$ & $0.001^{*}$ \\
\hline$\| \mathrm{A}$ & $33(30.56)$ & 0.0056 & $0.0015(0.0001-0.0682)$ & \\
\hline$\| \mathrm{B}$ & $46(42.59)$ & 0.0069 & $0.0008(0.0000-0.0842)$ & \\
\hline III + IV & $14(12.96)$ & 0.0380 & $0.0076(0.0003-0.2350)$ & \\
\hline \multicolumn{5}{|c|}{ Serum CA19-9 $9^{b}$ level } \\
\hline$\leq 39 \mathrm{KU} / \mathrm{l}$ & $31(28.70)$ & 0.0155 & $0.0009(0.0000-0.2350)$ & 0.965 \\
\hline >39KU/I & $77(71.30)$ & 0.0073 & $0.0011(0.0000-0.8423)$ & \\
\hline \multicolumn{5}{|c|}{ Serum CA50 ${ }^{C}$ level } \\
\hline$\leq 25 \mathrm{KU} / \mathrm{l}$ & $49(45.37)$ & 0.0152 & $0.0009(0.0000-0.2350)$ & 0.894 \\
\hline$>25 \mathrm{KU} / \mathrm{I}$ & $59(54.63)$ & 0.0050 & $0.0011(0.0000-0.0829)$ & \\
\hline \multicolumn{5}{|l|}{ Serum CEA ${ }^{d}$ level } \\
\hline$\leq 5 \mu \mathrm{g} / \mathrm{l}$ & $64(59.26)$ & 0.0093 & $0.0010(0.0000-0.0842)$ & 0.557 \\
\hline$>5 \mu \mathrm{g} / \mathrm{l}$ & $44(40.74)$ & 0.0101 & $0.0011(0.0000-0.2350)$ & \\
\hline
\end{tabular}

TNM $^{\mathrm{a}}$, tumor-node-metastasis; CA19-9 ${ }^{\mathrm{b}}$, carbohydrate antigen $19-9 ; \mathrm{CA}^{\mathrm{c}}$, carbohydrate antigen $50 ;$ CEA $^{\mathrm{d}}$, carcinoembryonic antigen; ${ }^{*} P<0.05$.

specificity for survival outcome. The area under the ROC curve was 0.861 (95\% CI: 0.784-0.938, $P=0.000$ ).

The Kaplan-Meier survival curves showed that postoperative survival was shorter for patients with high $(\geq 0.0044)$ MUC4/Y expression compared to patients with low $(<0.0044)$ expression $(P=0.002$, log rank test; Figure 1D).

As shown in Figure 2, the survival of patients with tumors occurring in the body or tail of the pancreas, poor tumor differentiation, TNM staging of III + IV, high serum $(>39 \mathrm{kU} / \mathrm{L})$ of CA19-9, high serum $(>5 \mu \mathrm{g} / \mathrm{L})$ of
CEA, high $(\geq 0.056)$ MUC4/Y expression was significantly worse than those with tumors occurring in the head of the pancreas $(P=0.020$, log rank test $)$, well and moderate tumor differentiation $(P<0.001$, log rank test), TNM staging of $\mathrm{A}+\mathrm{IB}$ or IIA or IIB $(P=0.003$, log rank test), low serum level of CA19-9 $(P=0.009$, log rank test $)$, low serum level of $\operatorname{CEA}(P=0.025$, log rank test $)$, low MUC4/Y expression $(P<0.001$, log rank test $)$, respectively. There were no significant associations between survival and patient gender, age, tumor size, nerve infiltration $(P=0.489,0.173,0.340,0.689$, respectively; log rank test). 


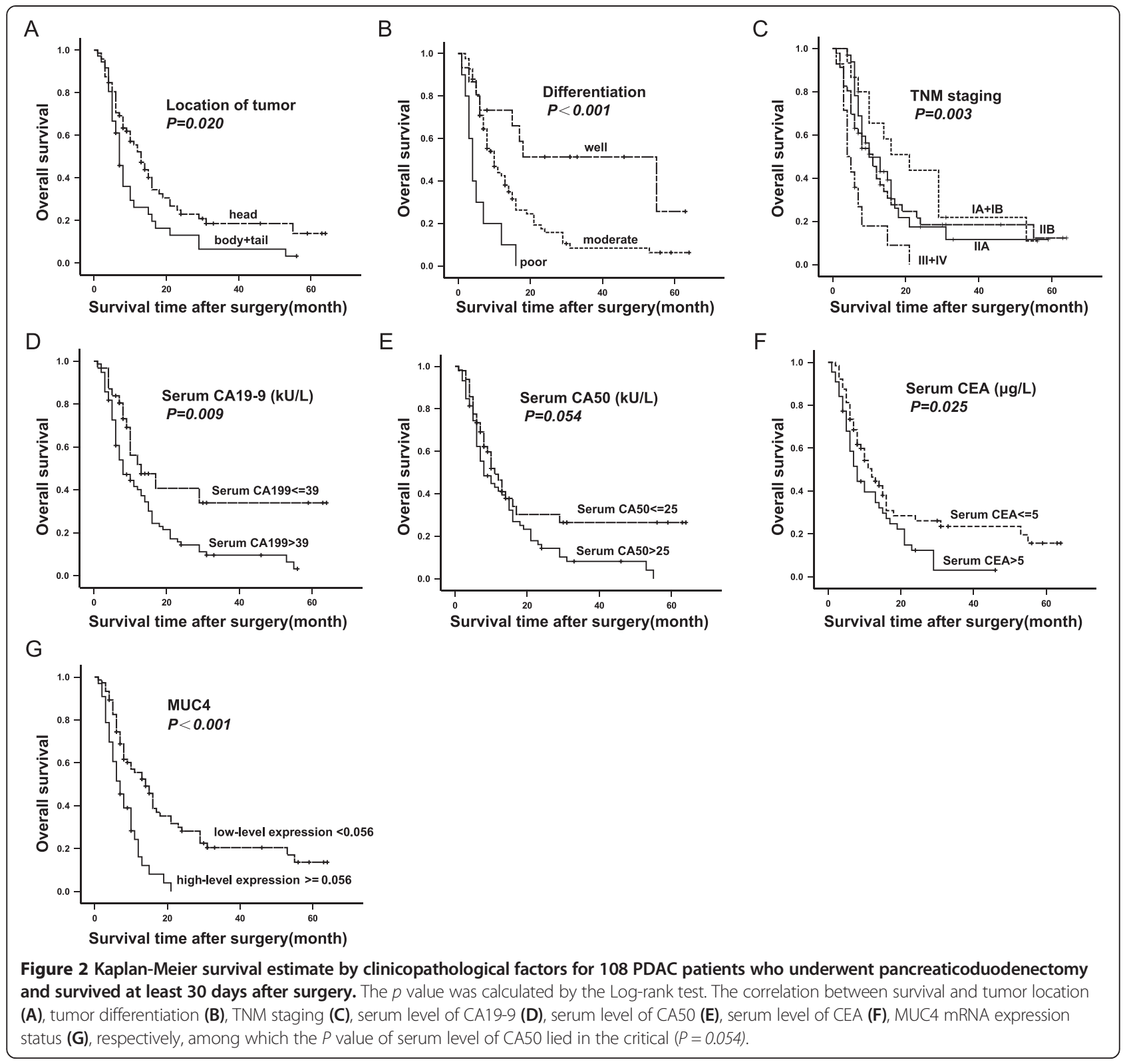

The log rank test showed the $P$ value of serum level of CA50 lied in the critical $(P=0.054)$.

Using $P=0.10$ as the cut-off value, eight factors (tumor location, tumor differentiation, TNM stage, serum carbohydrate antigen [CA]19-9, serum CA50, serum carcinoembryonic antigen, MUC4 expression, and MUC4/Y expression) were selected from the univariate analysis data (Table 2) for forward or backward stepwise multivariate Cox proportional hazard analysis (Table 3). Forward stepwise multivariate Cox analysis determined that tumor differentiation $(P=0.001$; hazard ratio [HR], moderate: $2.368,95 \%$ CI: $1.120-5.007$; HR, poor: 6.603 , 95\% CI: 2.515-17.338), serum CA19-9 $(P=0.021$; HR: 1.914, 95\% CI: 1.105-3.318), and MUC4 expression $(P=0.001$; HR: $2.281,95 \%$ CI: $1.415-3.677)$ were significant independent risk factors. Backward stepwise multivariate Cox analysis determined that tumor location $(P=0.001$; HR: 2.452, 95\% CI: 1.414-4.253), tumor differentiation $(P<0.001$; HR, moderate: 2.163 , 95\% CI: 0.994-4.706; HR, poor: $7.076,95 \%$ CI: $2.655-18.857)$, TNM stage $(P=0.014$; HR, IIA: 3.395, 95\% CI: 1.414-8.148; HR, IIB: 3.551, 95\% CI: 1.523-8.277; HR, III + IV: 4.218, 95\% CI: 1.652-10.768), serum CA19-9 $(P=0.008$; HR: $2.817,95 \% \mathrm{CI}: 1.313-$ 6.043), and MUC4 expression ( $P=0.010$; HR: $1.976,95 \%$ CI: 1.174-3.326) were significant independent risk factors.

\section{MUC4/Y stable overexpression}

To investigate the role of MUC4/Y in pancreatic cancer, PANC-1 cells, which do not express endogenous MUC4 [22], were infected with viral supernatant containing 
Table 2 Univariate analysis of prognostic factors

\begin{tabular}{|c|c|c|c|c|c|}
\hline Variable & Cases & Events & Mean survival (months) & $\mathrm{HR}^{\mathrm{a}}\left(95 \% \mathrm{Cl}^{\mathrm{b}}\right)$ & $p$ \\
\hline Gender & & & & & 0.504 \\
\hline Male & 61 & 47 & 16.176 & 1 & \\
\hline Female & 47 & 37 & 19.699 & $0.862(0.559-1.331)$ & \\
\hline Age (y) & & & & & 0.176 \\
\hline$<60$ & 47 & 35 & 21.381 & 1 & \\
\hline$\geq 60$ & 61 & 49 & 15.254 & $1.352(0.874-2.092)$ & \\
\hline Location of tumor & & & & & $0.026^{*}$ \\
\hline Head & 72 & 52 & 20.770 & 1 & \\
\hline Body and tail & 36 & 32 & 12.235 & $1.655(1.062-2.579)$ & \\
\hline Size of tumor $(\mathrm{cm})$ & & & & & 0.358 \\
\hline$\leq 2$ & 22 & 67 & 20.116 & 1 & \\
\hline$>2$ & 86 & 17 & 17.290 & $1.285(0.753-2.192)$ & \\
\hline Differentiation & & & & & $<0.001^{*}$ \\
\hline Well & 15 & 8 & 34.953 & 1 & \\
\hline Moderate & 83 & 66 & 15.803 & $2.532(1.202-5.332)$ & $0.015^{*}$ \\
\hline Poor & 10 & 10 & 5.700 & 7.624 (2.918-19.916) & $<0.001^{*}$ \\
\hline Nerve infiltration & & & & & 0.699 \\
\hline No & 38 & 29 & 21.137 & 1 & \\
\hline Yes & 70 & 55 & 16.406 & $1.094(0.694-1.725)$ & \\
\hline TNM staging & & & & & $0.007^{*}$ \\
\hline$|A+| B$ & 15 & 12 & 24.448 & 1 & \\
\hline$\| \mathrm{A}$ & 33 & 25 & 17.483 & $1.371(0.684-2.751)$ & 0.374 \\
\hline$\| \mathrm{B}$ & 46 & 34 & 18.785 & $1.507(0.777-2.925)$ & 0.225 \\
\hline$I I I+I V$ & 14 & 13 & 6.982 & $3.729(1.664-8.358))$ & $0.001^{*}$ \\
\hline Serum CA19-9 (kU/L) & & & & & $0.014^{*}$ \\
\hline$\leq 39$ & 31 & 16 & 28.993 & 1 & \\
\hline$>39$ & 77 & 68 & 14.556 & $1.988(1.150-3.436)$ & \\
\hline Serum CA50 (kU/L) & & & & & $0.065^{*}$ \\
\hline$\leq 25$ & 49 & 30 & 24.091 & 1 & \\
\hline$>25$ & 59 & 54 & 14.459 & 1.529 (0.975-2.398) & \\
\hline Serum CEA ( $\mu \mathrm{g} / \mathrm{L})$ & & & & & $0.032^{*}$ \\
\hline$\leq 5$ & 64 & 44 & 22.116 & 1 & \\
\hline$>5$ & 44 & 40 & 12.072 & 1.609 (1.041-2.488) & \\
\hline$\overline{M U C 4}\left(2^{-\Delta C t}\right)$ & & & & & $<0.001^{*}$ \\
\hline Low $(<0.056)$ & 75 & 54 & 22.101 & 1 & \\
\hline High ( $\geq 0.056)$ & 33 & 30 & 8.054 & $2.595(1.612-4.179)$ & \\
\hline$\overline{M U C 4 / Y ~\left(2^{-\Delta C t}\right)}$ & & & & & $0.003^{*}$ \\
\hline Low $(<0.0044)$ & 79 & 58 & 21.126 & 1 & \\
\hline High ( $\geq 0.0044)$ & 29 & 26 & 8.835 & $2.077(1.283-3.365)$ & \\
\hline
\end{tabular}

${ }^{\mathrm{a}} \mathrm{HR}$, hazard ratio; ${ }^{\mathrm{b}} \mathrm{Cl}$, confidence interval; ${ }^{*} \mathrm{P} \leq 0.10$.

either MUC4/Y or empty lentiviral expression plasmids for effective MUC4/Y overexpression or to serve as controls, respectively. Pooled populations of Puro-tagged stable transfected sub-lines were selected using $10 \%$ DMEM containing puromycin $(2.0 \mu \mathrm{g} / \mathrm{mL})$.
We examined stable MUC4/Y overexpression in PANC1-MUC4/Y cells at transcript and protein level using realtime PCR and immunoblotting, respectively; the negative and blank controls were mock-transfected cells (PANC1-EV) and parental wild-type PANC-1 cells, respectively. 
Table 3 Multivariate analysis of prognostic factors

\begin{tabular}{|c|c|c|c|c|}
\hline \multirow[t]{2}{*}{ Variable } & \multicolumn{2}{|l|}{ Forward stepwise } & \multicolumn{2}{|l|}{ Backward stepwise } \\
\hline & $\mathrm{HR}^{\mathrm{a}}\left(95 \% \mathrm{Cl}^{\mathrm{b}}\right)$ & $p$ & HR $(95 \% \mathrm{Cl})$ & $p$ \\
\hline Location of tumor & & 0.085 & & $0.001^{*}$ \\
\hline Head & - & & 1 & \\
\hline Body and tail & - & & $2.452(1.414-4.253)$ & \\
\hline Differentiation & & $0.001^{*}$ & & $<0.001^{*}$ \\
\hline Well & 1 & & 1 & \\
\hline Moderate & $2.368(1.120-5.007)$ & $0.024^{*}$ & $2.163(0.994-4.706)$ & 0.052 \\
\hline Poor & $6.603(2.515-17.338)$ & $<0.001^{*}$ & $7.076(2.655-18.857)$ & $<0.001^{*}$ \\
\hline TNM staging & & 0.175 & & $0.014^{*}$ \\
\hline$|A+| B$ & - & & 1 & \\
\hline$\| \mathrm{A}$ & - & 0.929 & $3.395(1.414-8.148)$ & $0.006^{*}$ \\
\hline$\| B$ & - & 0.922 & $3.551(1.523-8.277)$ & $0.003^{*}$ \\
\hline$I I I+I V$ & - & 0.077 & $4.218(1.652-10.768)$ & $0.003^{*}$ \\
\hline Serum CA19-9 (kU/L) & & $0.021^{*}$ & & $0.008^{*}$ \\
\hline$\leq 39$ & 1 & & 1 & \\
\hline$>39$ & $1.914(1.105-3.318)$ & & $2.817(1.313-6.043)$ & \\
\hline Serum CA50 (kU/L) & & 0.535 & & 0.085 \\
\hline$\leq 25$ & - & & 1 & \\
\hline$>25$ & - & & $0.552(0.280-1.086)$ & \\
\hline Serum CEA ( $\mu \mathrm{g} / \mathrm{L})$ & & 0.265 & & 0.089 \\
\hline$\leq 4.3$ & - & & 1 & \\
\hline$>4.3$ & - & & $1.554(0.934-2.584)$ & \\
\hline MUC4 $\left(2^{-\Delta C t}\right)$ & & $0.001^{*}$ & & $0.010^{*}$ \\
\hline Low $(<0.056)$ & 1 & & 1 & \\
\hline High ( $\geq 0.056)$ & $2.281(1.415-3.677)$ & & $1.976(1.174-3.326)$ & \\
\hline$M U C 4 / Y\left(2^{-\Delta C t}\right)$ & & 0.067 & & 0.243 \\
\hline Low $(<0.0044)$ & - & & - & \\
\hline High ( $\geq 0.0044)$ & - & & - & \\
\hline
\end{tabular}

We assessed MUC4/Y quantitatively using real-time RT-PCR with gene-specific priming (Figure 1A). The level of $M U C 4 / Y$ mRNA expression was normalized to that of $18 \mathrm{~S}$ rRNA. MUC4/Y expression in PANC-1MUC4/Y cells was 9912-fold and 9808-fold higher than that in the blank and negative controls, respectively (Figure 3A).

In agreement with the mRNA findings, western blotting confirmed MUC4/Y overexpression in the PANC1-MUC4/Y cells. The selected monoclonal antibody (\#ab60720; Abcam) is specifically directed against amino acids 79-189 of human MUC4, which are included in the protein expressed by the $M U C 4 / Y$ target gene. Figure 3B depicts a band that had migrated a distance consistent with the expected 133-kDa molecular weight of MUC4/Y. The blank and negative control cells were negative for MUC4 expression. HPAC, a MUC4-overexpressing pancreatic cell line, was used as a positive control for specific antibody [13].

We used the MUC4 monoclonal antibody to examine the subcellular localization of MUC4/Y using immunofluorescence. The pancreatic cancer cell line BXPC-3 is MUC4 positive-expression as positive control [13]. In BXPC-3 cells, there was both membranous and cytoplasmic staining for MUC4 (Figure 3C). A similar distribution was observed for PANC-1-MUC4/Y cells. MUC4/Y and wildtype MUC4 had similar sub-cellular localization, indicating similar MUC4 and MUC4/Y processing in the cells.

MUC4/Y contributed to enhance proliferation under lownutritional-pressure, anti-apoptosis, motility, invasiveness, and HUVEC endotube formation in PANC-1 cells in vitro Figure 4A shows that there was no significant difference for PANC-1-MUC4/Y cells grown in 10\% serum compared 
A

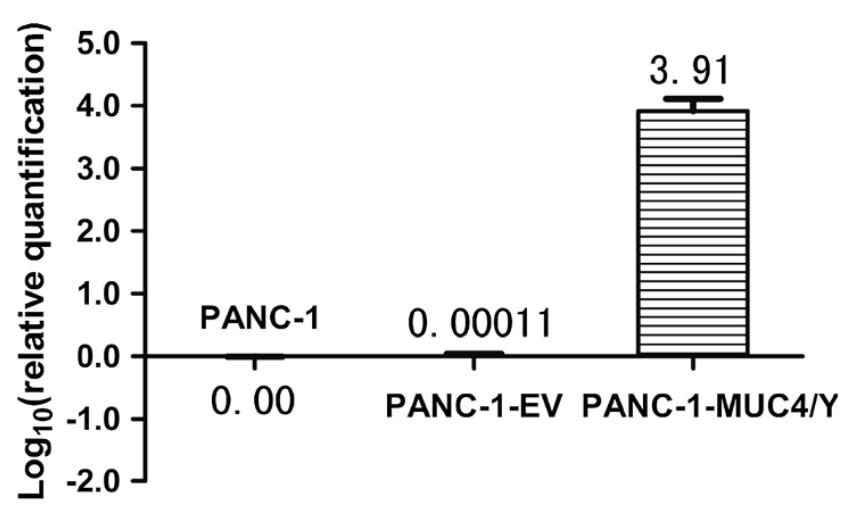

B

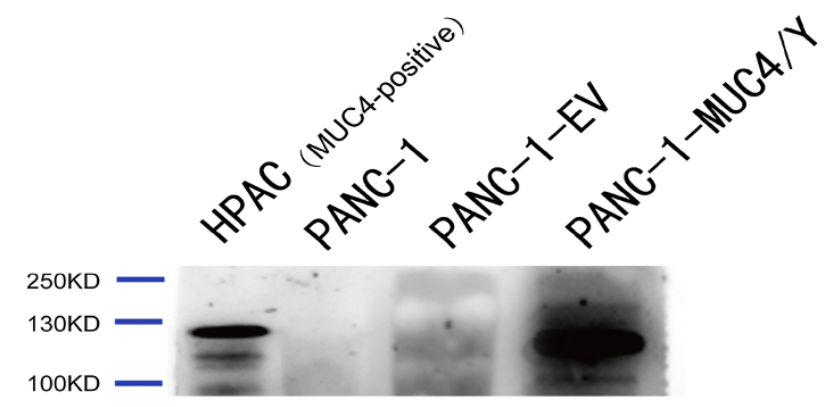

$37 K D$

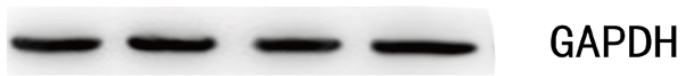

C
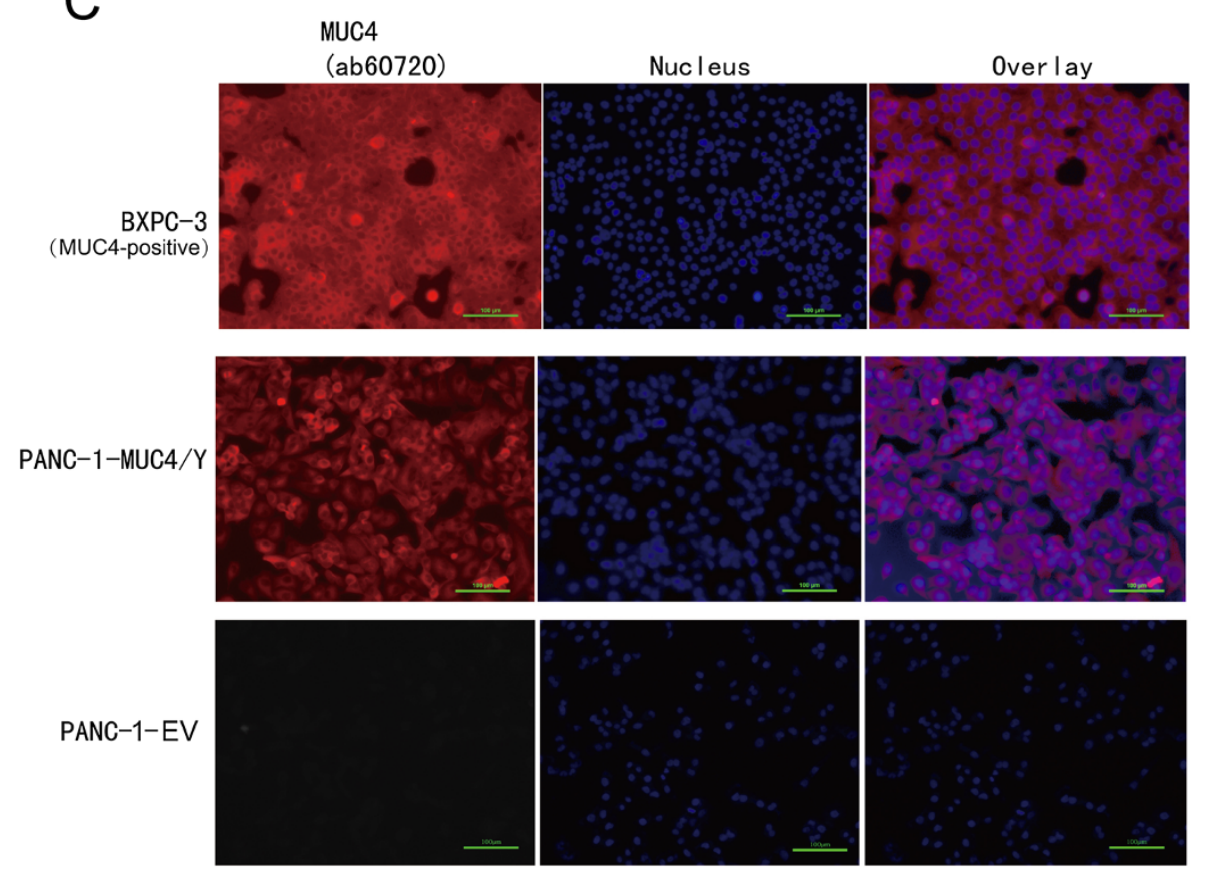

Figure 3 MUC4/Y expression and subcellular localization in PANC-1 cells. (A) Real-time PCR using specific primers and TaqMan probe to examine MUC4/Y transcript expression in PANC-1-EV cells and PANC-1-MUC4/Y cells. The level of target gene expression in the PANC-1-MUC4/Y cells was 9912-fold and 9808-fold higher than that of the blank control and negative control, respectively. (B) Western blot confirmation of MUC4/Y protein expression. Total protein from cell extracts was resolved on precast gels. The signal was detected using an electrochemiluminescence reagent kit. (C) Immunofluorescence demonstrating MUC4/Y subcellular localization similar to that of wild-type MUC4. The pancreatic cancer cell lines of HPAC and BXPC-3 is MUC4 positive-expression as positive control for specific antibody. 
A
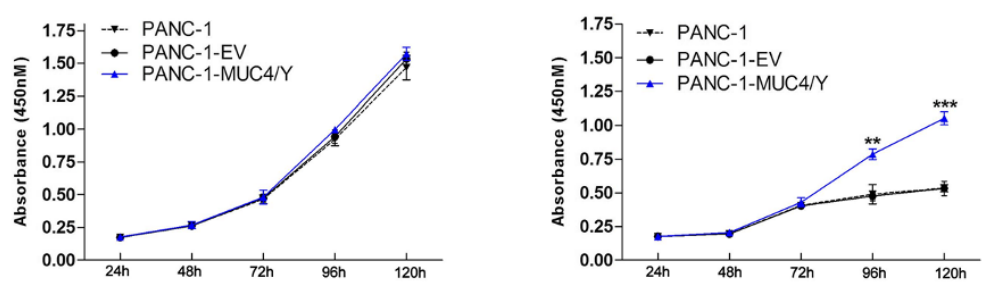

B

Apoptosis induced by $8 \mu \mathrm{M}$ Sorafenib for $24 \mathrm{~h}$
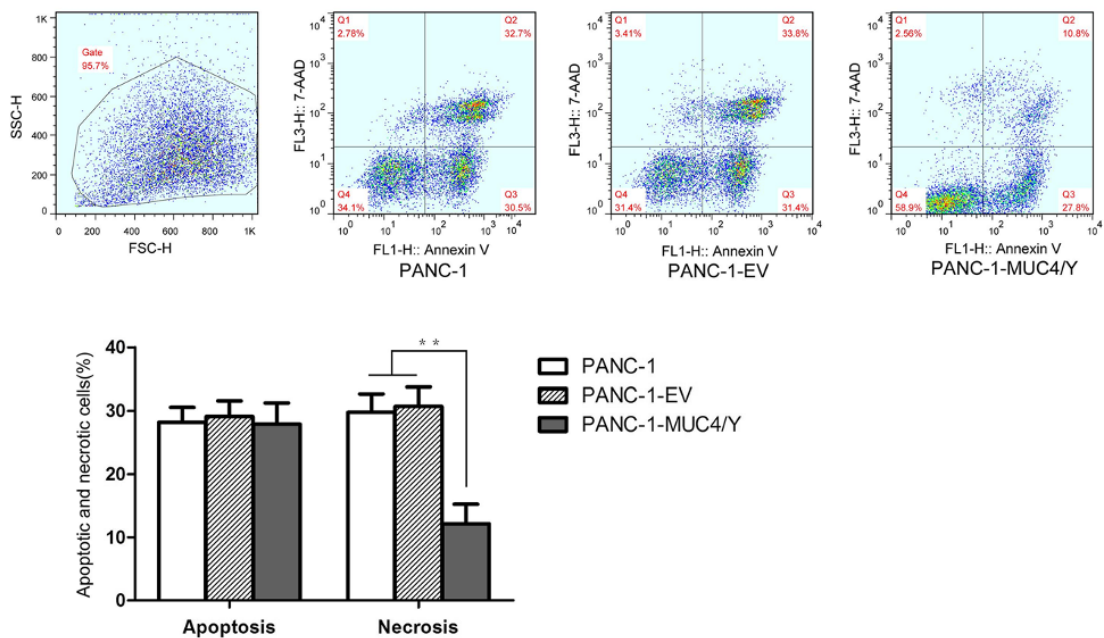

C

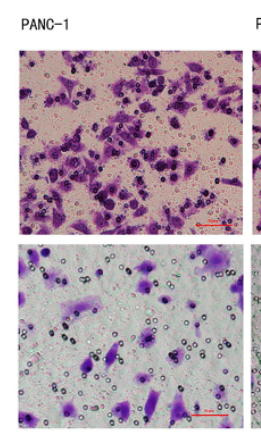
PANC-1-EV

PANC-1-MUC4/Y
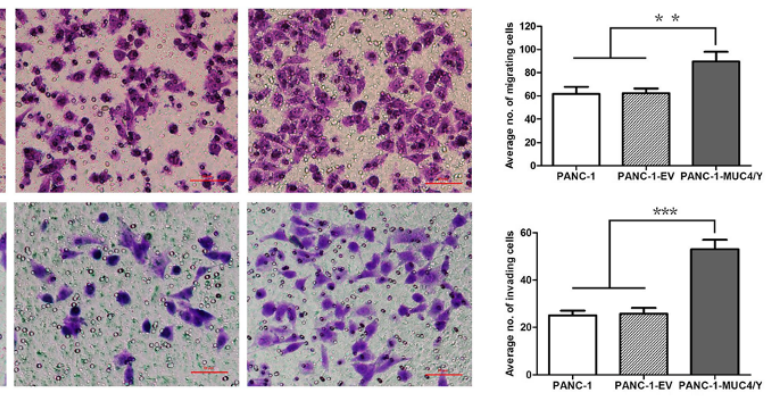

D PANC-1

PANC-1-EV
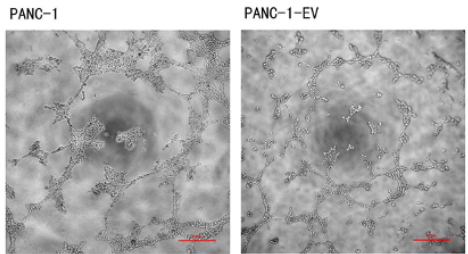

PANC-1-MUC4/Y
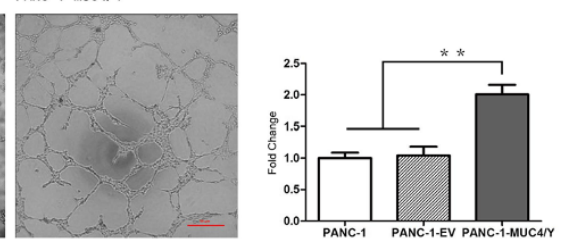

Figure 4 MUC4/Y enhances PANC-1 cell malignant activity in vitro. Data from three repeated experiments are presented as means \pm SD. ${ }^{*} P<0.01$, ${ }^{* * *} P<0.001$ vs. controls. (A) MUC4/Y enhanced in vitro proliferation of PANC-1 cells under stress from low nutritional status. The absorbance values of cells at different time points were detected with WST-8 dye. Cells were maintained in medium containing $10 \%$ serum (left) and $1 \%$ serum (right). (B) MUC4/Y increased resistance to apoptotic reagents, i.e., sorafenib. Representative templates of FACS analysis showing the proportion of cells positive for annexin $V$ and 7-AAD (top right quadrant) representing the percentage of necrotic cells; the proportion of cells that were annexin $\mathrm{V}$-positive and 7-AAD-negative (bottom right quadrant) represented the percentage of apoptotic cells (top). Bar denotes the percentage of apoptotic and necrotic cells in PANC-1-derived clones (bottom). (C) MUC4/Y affected pancreatic cancer cell metastatic potential in vitro. Bar graph shows the number of PANC-1-derived clones that had migrated or invaded through the Matrigel. (D) MUC4/Y enhanced cancer cell-associated HUVEC endotube formation. Bar denotes the fold increase of the number of endotubes compared to the blank control. 
to the controls. However, under stress from low nutritional status ( $1 \%$ serum), there were significant increases in the proliferation of PANC-1-MUC4/Y cells compared to the blank controls at $96 \mathrm{~h}$ and $120 \mathrm{~h}(P=0.003,0.000$, respectively), suggesting that MUC4/Y enhances in vitro proliferation of PANC-1 cells under stress from low nutritional status.

To examine whether MUC4/Y enhances resistance to apoptosis in pancreatic cancer cells, PANC-1-MUC4/Y cells and the controls were treated with $8 \mu \mathrm{M}$ sorafenib for $24 \mathrm{~h}$ and apoptosis was assessed using flow cytometry. The proportion of cells positive for annexin $\mathrm{V}$ and 7AAD was significantly decreased $(P<0.01$, respectively) compared to the blank and negative controls (Figure $4 \mathrm{~B}$ ), suggesting that MUC4/Y plays an anti-apoptotic role in pancreatic cancer in vitro.

We used Transwells without or with Matrigel-coated membranes to examine cell migration and invasion, respectively, in vitro. The average number of migrating cells indicated the significantly increased migration ability of PANC-1-MUC4/Y cells compared to that of the controls $(P<0.01$, respectively). Figure $4 \mathrm{C}$ shows that the number of PANC-1-MUC4/Y cells invading through the Matrigel was significantly higher than that of the controls $(P<0.001$, respectively). These data suggest that MUC4/Y can affect the metastatic potential of pancreatic cancer cells in vitro.

We also investigated whether MUC4/Y modulates the ability of PANC-1 cells to influence endotube formation by vascular endothelial cells. We used a 2-chamber coculture system to demonstrate the interaction between PANC-1 cells and HUVECs. Co-culturing HUVECs with PANC-1-MUC4/Y cells significantly enhanced HUVEC endotube formation $(P<0.01)$ compared to co-culture with the negative and blank controls (Figure 4D).

\section{MUC4/Y contributed to increase tumor growth and metastasis with rising proliferative activity, MVD, and metastasis incidence and decreased apoptosis in vivo}

To analyze the role of MUC4/Y in vivo, we developed subcutaneous and orthotopic models using PANC-1derived clones.

In the subcutaneous model, we used PANC-1-MUC4/ Y-Luc cells (negative control: PANC-1-EV-Luc) to obtain in vivo BLI, and the mean tumor growth rates at different time points determined by BLI (photons/s) were compared using repeated-measures analysis of variance (ANOVA) to identify subject-by-time profiles. Subcutaneously localized luciferase activity was identical in the two groups at the 2-hour time point, but at the 26, 30day time point, there was a statistically significant increase in the bioluminescent signal in PANC-1-MUC4/ Y-Luc cells compared to the negative control (Figure 5A), indicating that at the later stages, significant difference of tumor growth arised due to MUC4/Y-overexpression in vivo.

Moreover, at the 30-day time point, mice were sacrificed, and tumor sizes were measured. There was significant difference in tumor size between the two groups (Figure 5B, $P<0.05)$.

Ki-67 is an excellent marker of cell proliferation. Histologic evaluation of the tumors confirmed that MUC4/ Y-overexpression markedly increased the fraction of Ki-67positive tumor cells (the Ki-67 labelling index) compared to the controls $(P<0.05$, Figure $5 C$, the Second Line).

TUNEL was performed to assess the number of apoptotic cells in vivo. The proportion of TUNEL-positive PANC-1-MUC4/Y-Luc cells was significantly lower compared to the controls ( $P<0.05$, Figure $5 \mathrm{C}$, the Third Line).

We also assessed the effects of MUC4/Y overexpression on tumor vasculature by MVD analysis via CD31 staining of tumors vasculature (Figure $5 \mathrm{C}$, the Fourth Line). Compared to the controls, MUC4/Y significantly increased MVD in the subcutaneous tumors $(P<0.05)$.

Given the importance of the microenvironment in cancer pathogenesis, we developed a pancreatic orthotopic model to observe metastasis using PANC-1-derived clones with or without MUC4/Y overexpression. We confirmed metastasis by visual and histological inspection (Figure 6A-B). We also used in vivo BLI to confirm that the metastases were not related to tumor cell spillage at the time of orthotopic implantation (Figure 6A-2). The overall tumor incidence between the two groups was not significantly different. However, there were higher incidences of metastasis at different sites in the MUC4/Y-overexpressing group compared to the control groups (Figure 6C), including tumor spread in the spleen (6/8 vs. $4 / 7, P=0.608)$, liver (7/8 vs. $3 / 7, P=0.119)$, peritoneum $(5 / 8$ vs. $3 / 7, P=0.619)$, mesenteric lymph nodes $(5 / 8$ vs. $2 / 7, P=0.315)$, diaphragm $(2 / 8$ vs. $1 / 7, P=$ $1.000)$, intestinal wall ( $4 / 8$ vs. $0 / 7, P=0.026)$, and lung (6/8 vs. $1 / 7, P=0.041)$, suggesting that MUC4/Y overexpression promoted tumor metastasis (intestinal wall) and distant metastasis (lung) significantly effectively. Vein tumor thrombi were obvious in the PANC-1-MUC4/Y group (Figure 6B-6), suggesting that MUC4/Y overexpression aids in PANC-1 cell hematogenous metastasis.

In sum, the above-mentioned data confirmed that the overexpression-MUC4-Y resulted in increasing tumor growth and metastasis in vivo.

\section{DEG screening and functional annotation for global mRNA analysis of PANC-1-MUC4/Y- cells}

Using DGE analysis, we compared PANC-1-MUC4/Y cells to the blank and negative controls to identify the overlapping differential genes based on re-sampling tests and elimination of negative vector and random insert effects. Comparative analyses of MUC4/Y-associated 


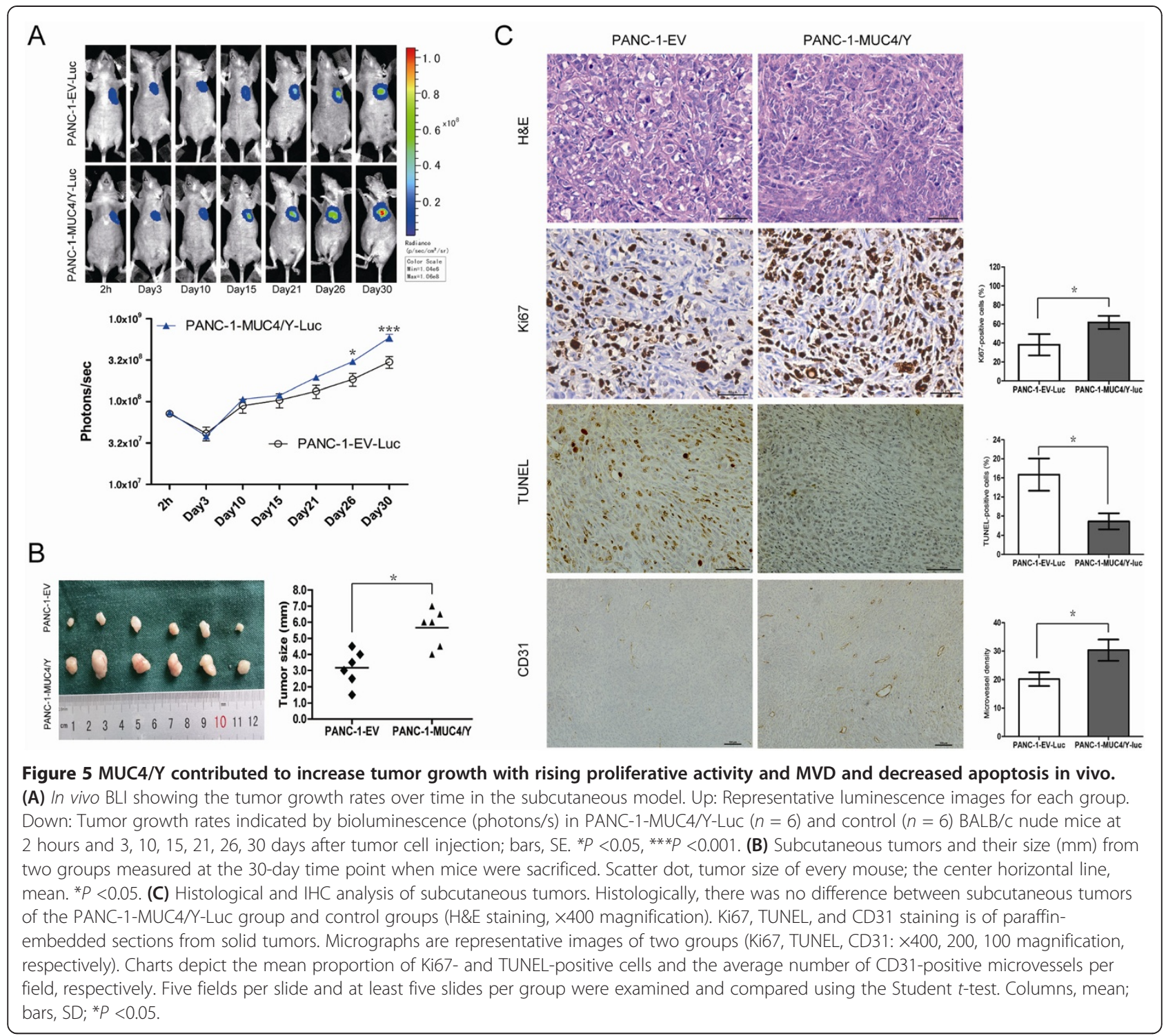

signatures revealed 3446 and 4149 differential genes for the blank and negative control cell lines, respectively, including 1575 overlapping genes [see Additional file 1: Table S4 lists the DEGs, intersection set of PANC-1MUC4/Y compared to the controls, respectively, absolute value of $\log 2$ ratio $\geq 1]$.

To understand the DEG global functions, we carried out enrichment analysis of GO function [23] and the KEGG pathway [24]. Additional file 1: Table S5 lists the detailed results of the GO enrichment analysis, indicating that MUC4/Y overexpression not only resulted in transcriptional change of the transmembrane, which is intrinsic to membrane and extracellular region-associated proteins for cytokine activities that control tissue and cell survival, growth, differentiation, and effector function, but also altered interactions between the cell and its surroundings, and intracellular signaling and signal transmission.

Enrichment analysis with KEGG confirmed that the set of 1575 DEGs was enriched for pathways not only correlated to cancer, but also were associated with MUC4, as shown in the literature database (Additional file 1: Table S6), and was consistent with the GO functional enrichment analysis.

Verification of DEGs related with the malignant functions of MUC4/Y and VEGF family molecules

To evaluate the malignant functions of MUC4/Y, we summarized the distribution of DEGs in a number of pathways markedly related to the malignance of cancer using Database for Annotation, Visualization, and Integrated 


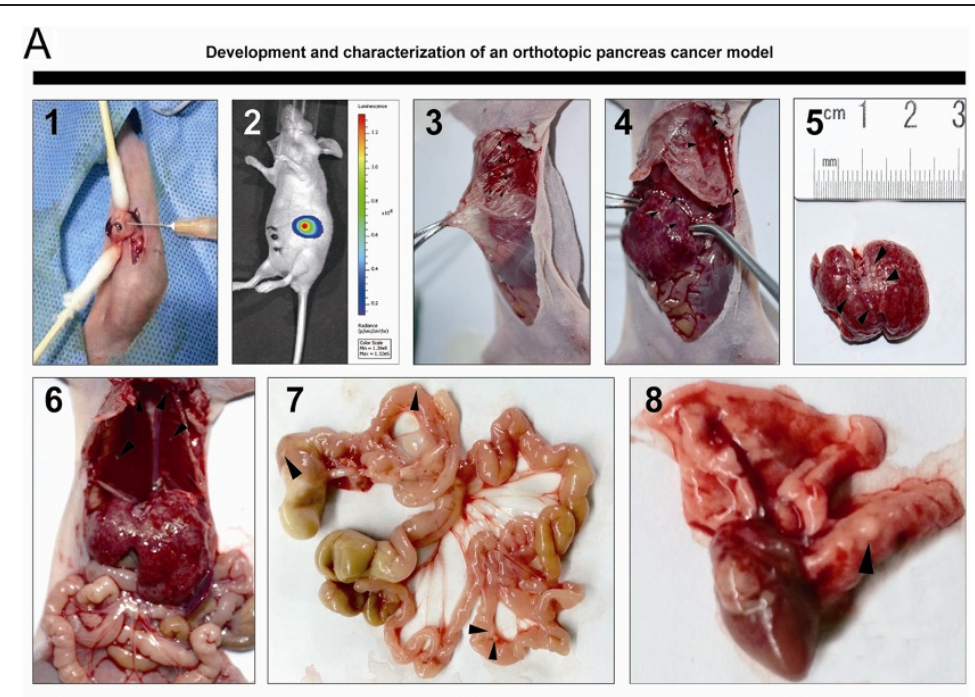

B

The hemotoxalin and eosin staining of metastatic lesions
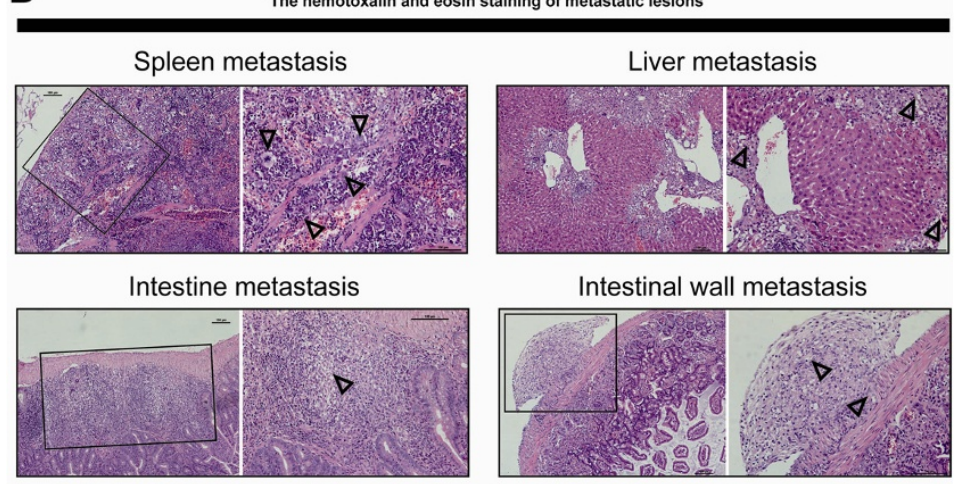

Lung metastasis
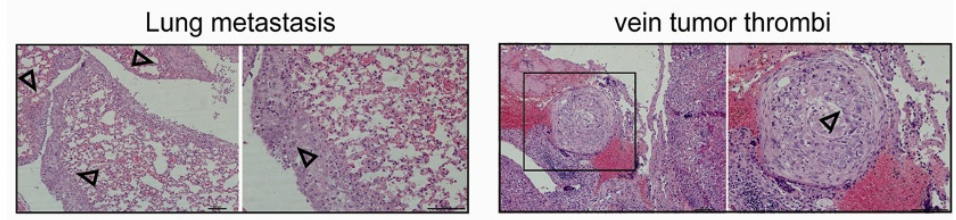

C

Incidence of metastases developed by orthotopic implantation

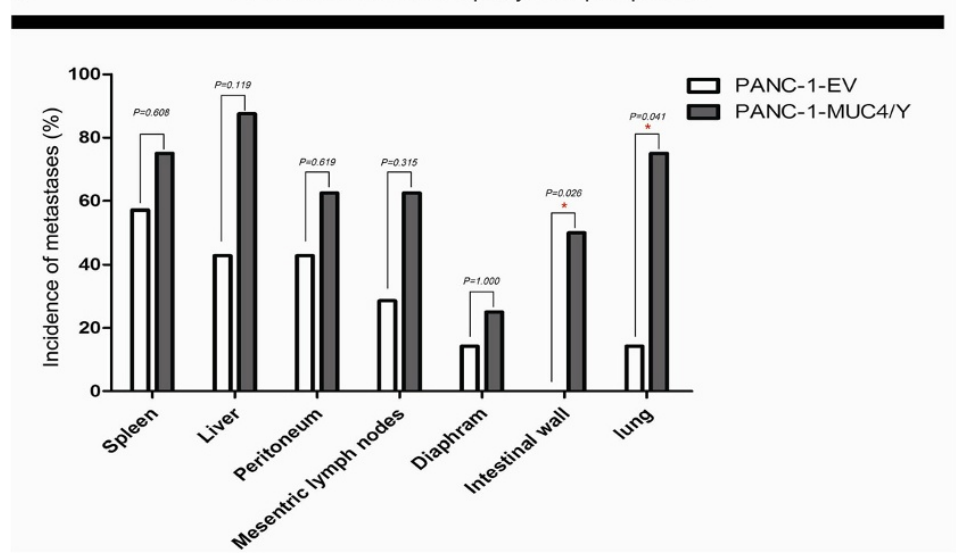

Figure 6 (See legend on next page.) 
Discovery (DAVID, LIB) software and KEGG annotations (Figure 7A).

For qPCR validation, we selected a batch of DEG molecules that play roles in the main pathways related to oncogenic transformation, based on the literature database. The independent qRT-PCR results for these genes were consistent with the DGE results (Figure 7B), indicating that our sequencing approach and analytical pipeline were reliable.

For western blotting, we selected a batch of proteins related to DEG molecules, especially protein phosphorylation (Figure 7C). There was a MUC4/Y-dependent increase of ErbB2 phosphorylation activation, paralleled by the upregulation of key molecules (Ras, Src, focal adhesion kinase [FAK], extracellular signal-regulated kinase [ERK], c-Jun amino-terminal kinase [JNK], AKT, nuclear

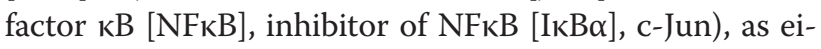
ther total or phosphorylated proteins, in the downstream signaling pathways.

Based on the results demonstrating the effect of MUC4/Y associated with angiogenesis and metastasis in malignant progression of pancreatic cancer, we verified the expression change of the key factors in cell culture supernatants with ELISA, combined with validation of their mRNA expression by qRT-PCR. MUC4/Y overexpression up-regulated the transcriptional level of VEGFA and VEGFB compared to the control, but down-regulated VEGFC transcriptional level (Figure 7B). MUC4/Y overexpression significantly increased PANC-1-MUC4/Y cell output of both VEGF (main detection of VEGFA) and IL8/CXCL8 into the medium after 24-h or 48-h incubation compared to the control (Figure 7D).

\section{Discussion}

We designed specific primers and a TaqMan probe (Figure 1A) for MUC4/Y and verified their specificity by sequencing the PCR products. We applied a strict statistical test which found that with the rise in levels of TNM stage, the level of MUC4/Y mRNA expression increased significantly. MUC4/Y expression at TNM stage IA + IB was significantly lower than that at TNM stage IIA, IIB-2 or III + IV, and its expression at IIA, IIB (including IIB-1,2) was significantly lower than that at III + IV, respectively. These suggest that MUC4/Y relates to the invasion, progression and distant metastases, which also coincides with the results of in vitro and in vivo experiments based on stable MUC4/Y-overexpressing pancreatic cancer cell models. The single discrepancy that we observed in the staging system is relatively minor. There is no significant difference between MUC4/ $\mathrm{Y}$ expression at TNM stage IA + IB and IIB-1(regional nodal involvement), and there was also no significant difference between MUC4/Y expression at TNM stage IIA and IIB-2 (regional nodal involvement). This may be because of the level of MUC4/Y mRNA expression is not associated with regional lymph node metastasis. The results of positive correlation between MUC4/Y and MUC4 expression levels in PDAC clinical samples also suggest that MUC4/Y might play similar roles as MUC4 in the malignant progression of PDAC patient.

Every univariate factor-specific overall survival was estimated by using the Kaplan-Meier method and compared with log-rank tests. Our results showed those variables identified by the Kaplan-Meier method as having predictive value were the same ones as by univariate analysis (Figure 2 and Table 2), which would be included in the multivariate analysis. Then the effect of potential confounding variables on survival was examined by using the multivariate Cox proportional hazard model after adjusting for confounding, including global and covariatespecific tests. Our results showed that as same as tumor location, tumor differentiation, TNM staging, serum level of CA19-9, serum level of CA50, serum level of CEA and MUC4 mRNA expression status, MUC4/Y mRNA expression level was also significant predictor of survival in univariate analysis. But only tumor location, tumor differentiation, TNM stage, serum CA19-9, and MUC4 expression were independently associated with survival differences in a multivariate Cox proportional hazards model, which are in accordance with previous reports $[10,11,25,26]$. These results suggest that the effect of MUC4/Y expression is less than the effect of MUC4 expression on survival. That might be because $M U C 4 / Y$ is only the one of splice variants of MUC4.

Using lentiviral transfection, we constructed and identified pancreatic cancer PANC-1 cell lines that stably overexpressed the MUC4/Y gene. The subcellular localization is similar to that of wild-type MUC4, indicating that all 


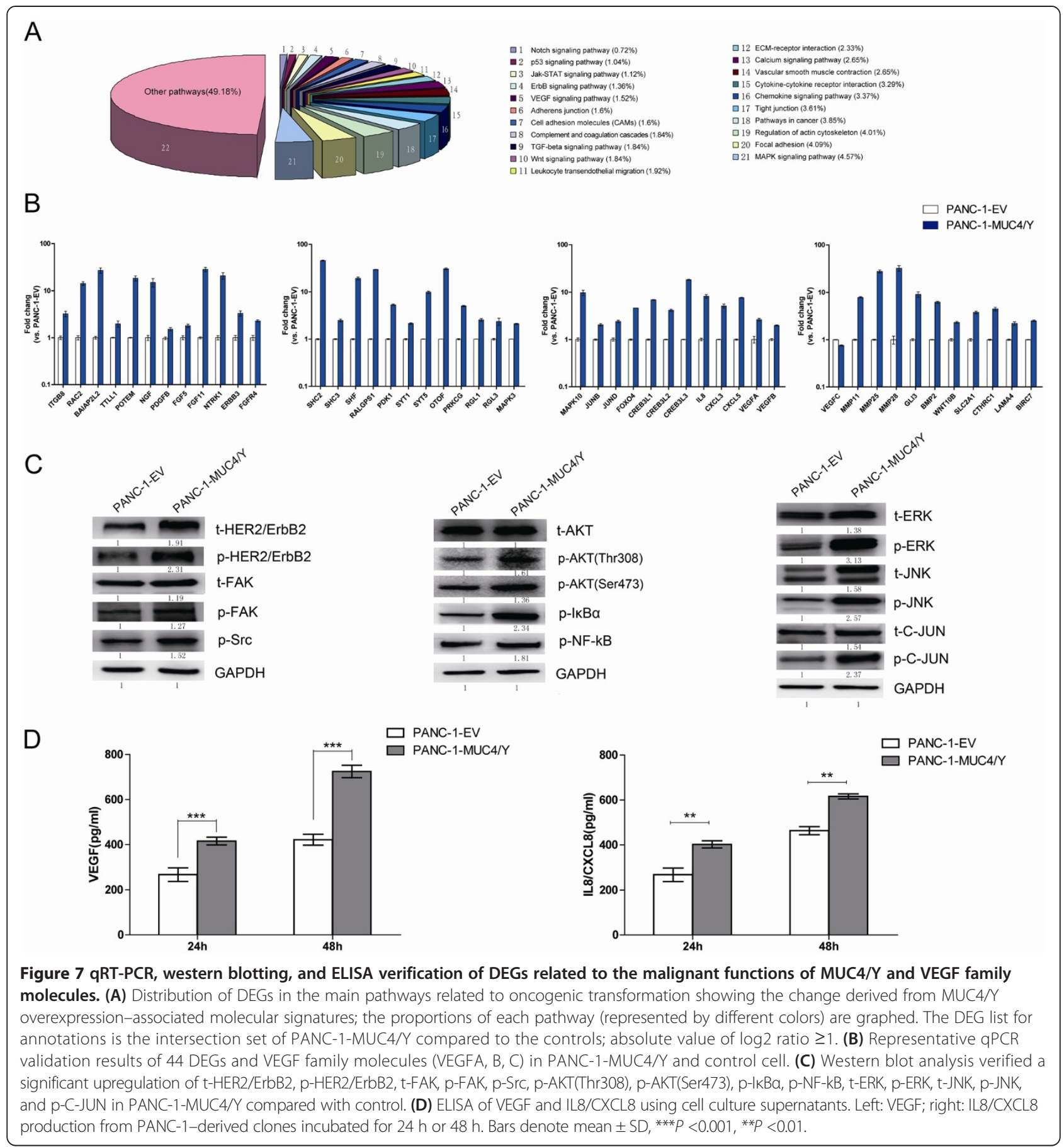

functional domains are expressed and processed accurately in our MUC4/Y-overexpressing cell model in agreement with that of wild-type MUC4. Based on the cell models, our results reveal that MUC4/Y contributes to enhance malignant activities that were observed in the experimental assay in vitro and in vivo, including proliferation, evasion or resistance to apoptosis, angiogenesis and metastasis.

Meanwhile, We noted that MUC4/Y enhanced in vitro proliferation of PANC-1 cells under stress from low nutritional status. Coincidentally, bioluminescence imaging revealed that MUC4/Y contributed to enhance the tumor growth rates in the subcutaneous model at the later stages (day26, 30 after injection). We speculate that MUC4/Y may be initiate survival signals, increase energy-generating ability or prevent the apoptosis to resist the stress from the lack of growth factors and energies. Additionally, the differences of growth rates between MUC4/Y-overexpressed PANC-1 cells and control in 
earlier stage were not observed probably due to the tumors not growing large enough to undergo an angiogenic switch. Furthermore, the detailed analyses of transcriptome changes caused by MUC4/Y gene support this inference. MUC4/Y not only up-regulates a series of genes (GLI family zinc finger 3, GLI3 [27]; bone morphogenetic protein 2, BMP2 [28]; winglesstype MMTV integration site family member $10 \mathrm{~B}$, WNT10B [29], IL8 [30], NGF [31]) related to the enhancement of cancer cell proliferation and increased transcription of apoptotic protein inhibitors (baculoviral IAP repeat containing $7, B I R C 7$ [32];), but also upregulates glucose transporter (SLC2A1/GLUT1) related to the increased energy-generating ability.

We developed a pancreatic orthotopic model to observe tumor spontaneous metastases by visual and histological inspection. Tumors developed at organ sites similarly as metastatic colonization by human PDAC metastases, including direct invasion to adjacent organs (spleen, intestine, peritoneum), regional lymph node metastases or dissemination by those (mesenteric lymph nodes, diaphragm), and distant metastasis (liver, lung). Our data indicate that MUC4/Y overexpression promoted adjacent metastasis (intestinal wall) and distant metastasis (lung) significantly effectively, which also is consistent with the positive correlation of MUC4/Y mRNA expression with tumor invasion and distant metastases in human PDAC clinic samples. Additionally, the effects of MUC4/Y on ascending malignant abilities(proliferation, anti-apoptosis, motility, invasiveness, angiogenesis) of tumor cells can also affect the metastatic potential of pancreatic cancer cells during multi-steps of metastasis process, including invasion, intravasation, extravasation, metastatic colonization. Notably, our data provide evidence for MUC4/Y upregulates ITGB8 downstream of the actin cytoskeleton pathway (ITGB8-FAK-Cas/CrkII/DOCK180 complex-RAC- IRSp53- WAVE2-Arp2/3-F-Actin/PFN complex) to affect actin dynamics and cancer cell motility [33].

Angiogenesis is critical for the continuous growth of tumors and the development of metastases. Our study provides evidence that MUC4/Y plays an initial role in tumor angiogenesis. We find and verify that MUC4/Y overexpression contributed to an array of crucial factors involved in angiogenesis: IL8 [34], CXCL3, CXCL5 [35], matrix metalloproteinase (MMP)11 [36], MMP25 [37], MMP28 [38], VEGF [39]. Interestingly, MUC4/Y upregulates the transcriptional level of VEGFA and VEGFB, but down-regulates VEGFC transcriptional level compared to the control. VEGF represents a family with multiple functions that affect tumor growth and metastasis. Specifically, VEGF-A is crucial for tumor angiogenesis and plays a key role in endothelial cell growth, migrationl, and permeability as a ligand for VEGFR-1 and VEGFR-2. VEGFB regulates the formation of blood vessels and are involved in endothelial cell physiology as a ligand for VEGFR-1 and NRP-1(neuropilin-1). The up-regulation of both of the above explains MUC4/Y contributes to tumor angiogenesis. The other isoform of VEGF, VEGFC and its specific receptor VEGFR-3 compose an essential signal pathway for lymphatic vessel growth in physiological and pathological conditions, more importantly in lymphatic spread of metastases. Intriguingly, the down-regulation of VEGFC coincides with MUC4/Y has no effect on regional lymph node metastases in pancreatic orthotopic model- mice and PDAC clinic samples, although more experiments may need to be confirmed.

Significantly, as shown in Figure 8, we investigated transcriptome changes caused by MUC4/Y expression using DGE technology, bioinformatics analysis and experimental verification, and have depicted a condensed version focusing on the malignant activity related pathways.

Importantly, we have found that EGF domain in MUC4/ $\mathrm{Y}$ and its interaction with ErbB2 and ErbB3 receptors trigger intrinsic protein-tyrosine kinase activity and further activate intracellular signaling pathways (e.g., mitogenactivated protein kinase [MAPK], phosphatidylinositol3-kinase $[\mathrm{PI} 3 \mathrm{~K}]-\mathrm{Akt}$, protein kinase $\mathrm{C}[\mathrm{PKC}]$ pathways), and coactivate transcription of the downstream effector molecules to mediate malignant functions of tumor cell, specifically, the production or upregulation of cytokines, growth factors, extracellular matrix (ECM), integrins (ITGs), and corresponding membrane receptors (CXCL3/ $5 / 8$, nerve growth factor [NGF], neurotrophic tyrosine receptor kinase type 1 [NTRK1], platelet-derived growth factor beta polypeptide [PDGFB], fibroblast growth factor [FGF]5/11, FGFR4, collagen triple helix repeat-containing 1 [CTHRC1], laminin alpha 4 [LAMA4], ITGB8; range: $1.27 \pm 0.20$-fold to $27.92 \pm 3.58$-fold increase). Notably, the transcription of cytokines, growth factors, ECM, and ITGs, and the interaction between them and the corresponding membrane receptors can in turn lead to upregulation of the signal transduction cascades, including the MAPK, PI3K-Akt, and PKC pathways. Thus, MUC4/Y expression that concomitantly elicits transcript-level upregulation of an array of molecules creates the positive feedback regulatory loops that would result in sustained upregulation of oncogenetic and progression signaling and lead to complex interplay or crosstalk between several signaling pathways.

Significantly, the above analysis and the novel finding that MUC4/Y triggers positive feedback loops related to malignant activity not only suggest that tumor cells can engage MUC4/Y to express survival factors concomitantly to resist adverse conditions in the microenvironment, e.g., in the circulatory systems during metastasis, but also suggest that tumor cells can exploit MUC4/Y expression to affect the tumor milieu by increasing the expression of 


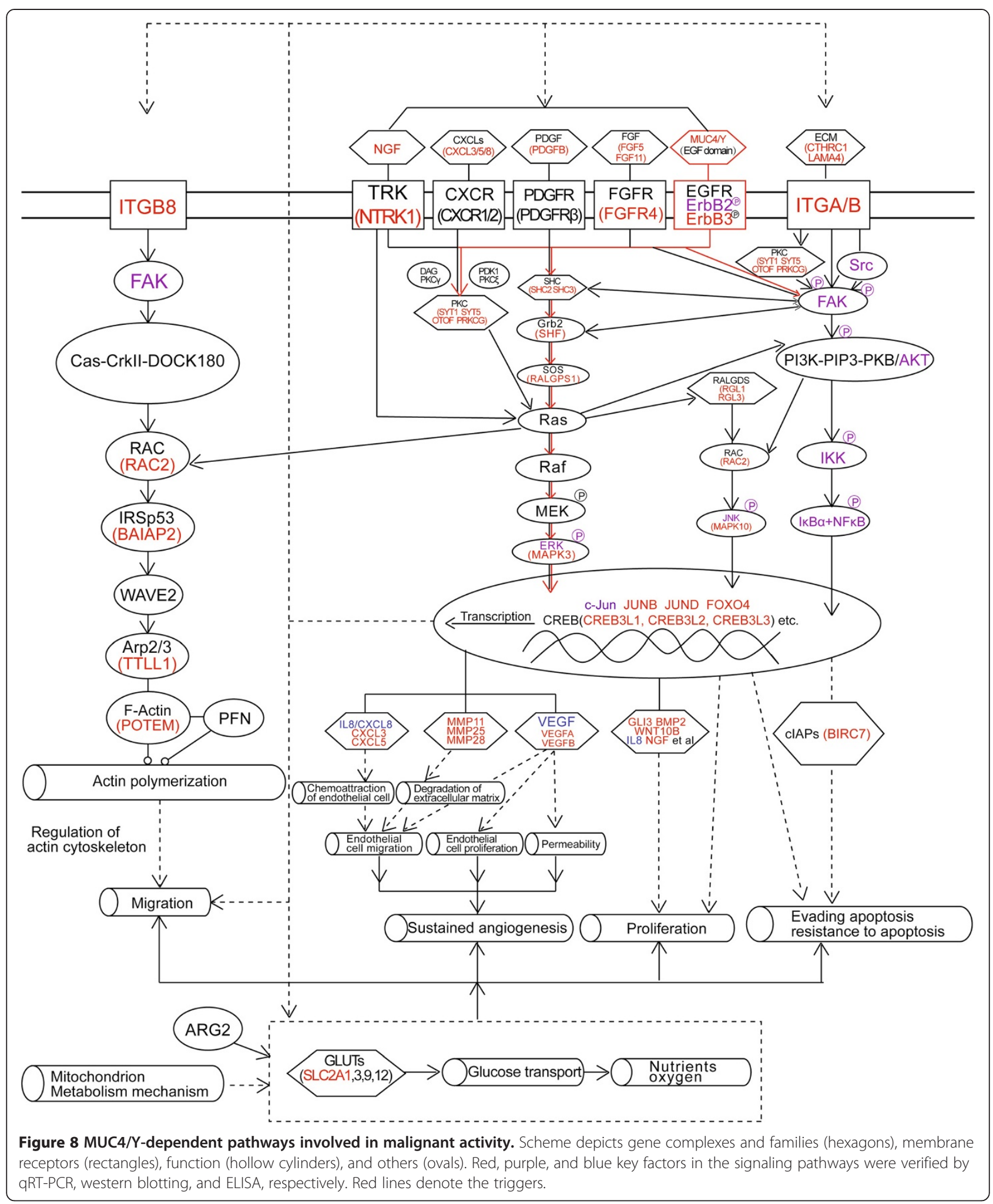

cytokines, growth factors, and adhesion molecules, although the lack of the TR domain mainly relates to cell-ECM and cell-cell interplay $[40,41]$.
Taken together, we provide evidence that supports the effects of MUC4/Y in the malignant progression of pancreatic cancer. These results on functional studies 
are consistent with similar trends compared to the results reported from experimental model of over-expression of rat orthologue of MUC4 (rMuc4/SMC) [42,43] and miniMUC4[21], or silencing/knockdown of MUC4 (sh-MUC4) $[40,44,45]$. Together with the positive correlation of MUC4/Y with MUC4 expression in PDAC clinical samples, we have validated our reasoning that MUC4/Y is involved in malignant progression similarly to FL-MUC4 and, consequently, MUC4/Y and its domain-lacking models may be valuable tools for the further dissection of MUC4-mediated functions and mechanisms.

Although we have pointed out the over-expression and alternative splicing of MUC4 may create a favorable environment for tumor progression by triggering malignancy-related positive feedback loops, it would be more expected to further investigate the interaction and network between those key mediators and their receptors, between involved signal pathways, as well as between transcription factors in the formation of circuit using new approaches like systems biology and clinical bioinformatics.

\section{Conclusions}

The huge length of its gene fragment restricts the functional and mechanism research of human MUC4. As one of its splice variants, MUC4/Y with coding sequence is mostly as similar as FL-MUC4. The level of MUC4/Y mRNA expression in PDAC clinical samples indicates that MUC4/Y is significantly positive-correlated with tumor invasion and distant metastases. The positive correlation between MUC4/Y and MUC4 expression levels in PDAC clinical samples also suggests that MUC4/Y might play similar roles as MUC4 in the malignant progression of pancreatic cancer. Forced-expression MUC4/Y has sub-cellular localization similar to that of wild-type MUC4, suggesting similar protein processing in the transfection cell model. Functional studies show that MUC4/Y enhances cell model malignant activity in vitro and in vivo, including proliferation under low-nutritional-pressure, resistance to apoptosis, motility, invasiveness, angiogenesis, and distant metastasis. Mechanism studies indicate the novel finding that MUC4/Y triggers malignancy-related positive feedback loops for concomitantly up-regulating the expression of survival factors to resist adverse microenvironment and increasing the expression of an array of cytokines and adhesion molecules to affect the tumor milieu. In light of the enormity of the potential regulatory circuitry in cancer afforded by MUC4 and/or MUC4/Y, repressing MUC4 transcription, inhibiting post-transcriptional regulation, including alternative splicing, or blocking various pathways simultaneously may be helpful for controlling malignant progression. MUC4/Y- expression model is proven to valuable tool for the further dissection of MUC4-mediated functions and mechanisms.

\section{Additional file}

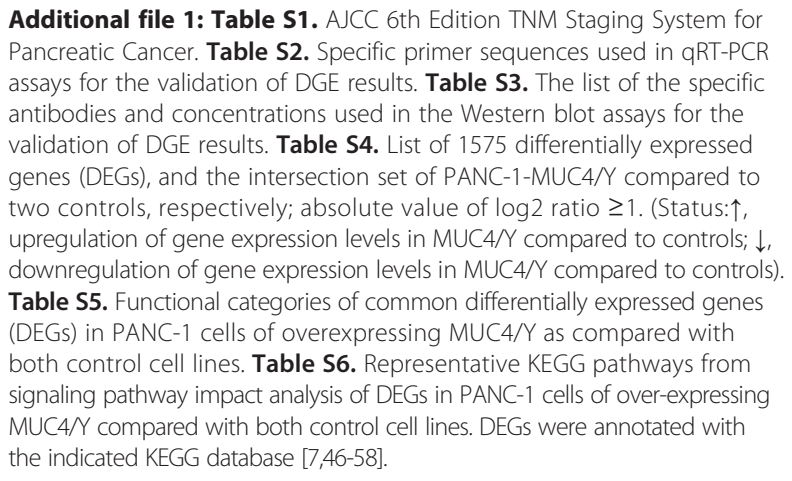

\section{Abbreviations}

7-AAD: 7-amino-actinomycin D; ANOVA: Analysis of variance;

BLI: Bioluminescence imaging; BIRC7: Baculoviral IAP repeat containing 7; BMP2: Bone morphogenetic protein 2; CDNA: Complementary DNA;

Cl: Confidence interval; Ct: Threshold cycle value; CTHRC1: Collagen triple helix repeat-containing 1; DEGs: Differentially expressed genes; DGE: Digital gene expression; DMEM: Dulbecco's modified Eagle's medium; ECM: Extracellular matrix; EGF: Epidermal growth factor-like domain; ELISA: Enzyme-linked immunosorbent assay; ERK: Extracellular signal-regulated kinase; EV: Empty lentiviral vectors; FACS: Fluorescence-activated cell sorter; FAK: Focal adhesion kinase; FBS: Fetal calf serum; FGF: Fibroblast growth factor; FL-MUC4: Full-length MUC4; GAPDH: Glyceraldehyde-3-phosphate dehydrogenase; GFP: Green fluorescent protein; GLI3: GLI family zinc finger 3; GLUT: Glucose transporter; GO: Gene Ontology; H\&E: Hematoxylin and eosin; HER2: Activation of human EGF receptor type 2; HR: Hazard ratio; HUVECs: Human umbilical vein endothelial cells; IL8: Interleukin-8; IHC: Immunohistochemistry; IKBa: Inhibitor of NFKB; ITGs: Integrins; JNK: c-Jun amino-terminal kinase; KEGG: Kyoto Encyclopedia of Genes and Genomes; LAMA4: Laminin alpha 4;

MAPK: Mitogen-activated protein kinase; MVD: Microvessel density; NGF: Nerve growth factor; NFKB: Nuclear factor KB; NIDO: The nidogen (NIDO) -like domain; NTRK1: Neurotrophic tyrosine receptor kinase type 1; OS: Overall survival; PBS: Phosphate-buffered saline; PDAC: Pancreatic ductal adenocarcinoma; PDGFB: Platelet-derived growth factor beta polypeptide; PDK: Pyruvate dehydrogenase kinase; PI3K: Phosphatidylinositol-3-kinase; PKC: Protein kinase C; qRT-PCR: Quantitative reverse transcription polymerase chain reaction; ROC: Receiver operating characteristic; RT: Reverse transcription; SD: Standard deviation; SV: Splice variants; TPM: Transcripts per million; TNM: Tumornode-metastasis; TR: Tandem repeat; TUNEL: Terminal deoxynucleotidyl transferase-mediated dUTP nick end labeling; WNT10B: Wingless-type MMTV integration site family member 10B; VEGF: Vascular endothelial growth factor.

\section{Competing interests}

The authors declare that they have no competing interests.

\section{Authors' contributions}

YZ and JJZ carried out the studies, participated in the experimental design, statistical and bioinformatics analysis, and drafted the manuscript. $\mathrm{KLX}$ performed cell culture and participated in the in vitro experiments. JT and WBL carried out the in vivo studies and participated in the statistical analysis. RZ and Yan Z participated in the histological examination of tissue samples. BW and JQT performed the GRT-PCR assays. XFZ and ZL performed the Western blotting, immunofluorescence and electron microscopy. WTG and KRJ participated in the sample collection, follow-up of patients and statistical analysis. ZKX and YM conceived the study, participated in its design and coordination, and helped to draft the manuscript. All authors read and approved the final manuscript.

\section{Acknowledgments}

This work was supported by grants from the National Natural Science Foundation of China $(81101802,81272712,81170336)$, the Natural Science Foundation of Jiangsu Province (BK2011845), the Program for Development 
of Innovative Research Team in the First Affiliated Hospital of NJMU, Priority Academic Program Development of Jiangsu Higher Education Institutions (PAPD, JX10231801), and the Research Special Fund for Public Welfare Industry of Health (201202007).

We thank Liang-Feng Zou and BGI (Shenzhen, China) for their technical assistance in DGE Sequence and bioinformatics analysis. We thank Elixigen Corporation (Huntington Beach, California, USA) for helping in proofreading and editing the English of final manuscript.

\section{Author details}

'Department of General Surgery, First Affiliated Hospital, Nanjing Medical University, 300 Guangzhou Road, Nanjing 210029, Jiangsu Province, People's Republic of China. ${ }^{2} J i a n g s u$ Province Academy of Clinical Medicine, Institute of Tumor Biology, Nanjing 210029, People's Republic of China. ${ }^{3}$ Jiangsu Province Blood Center, Nanjing 210042, People's Republic of China. ${ }^{4}$ Department of Pathology, Shanghai Medical College, Fudan University, Shanghai 200032, People's Republic of China. ${ }^{5}$ Department of Pathology, First Affiliated Hospital, Nanjing Medical University, Nanjing 210029, People's Republic of China. ${ }^{6}$ Department of General Surgery, the First Affiliated Hospital of Soochow University, Suzhou 215006, People's Republic of China.

Received: 14 May 2014 Accepted: 22 October 2014

Published online: 04 November 2014

\section{References}

1. Moniaux N, Escande F, Porchet N, Aubert JP, Batra SK: Structural organization and classification of the human mucin genes. Front Biosci 2001, 6:D1192-D1206.

2. Porchet N, Nguyen VC, Dufosse J, Audie JP, Guyonnet-Duperat V, Gross MS, Denis C, Degand P, Bernheim A, Aubert JP: Molecular cloning and chromosomal localization of a novel human tracheo-bronchial mucin CDNA containing tandemly repeated sequences of 48 base pairs. Biochem Biophys Res Commun 1991, 175:414-422.

3. Moniaux N, Nollet S, Porchet N, Degand P, Laine A, Aubert JP: Complete sequence of the human mucin MUC4: a putative cell membrane-associated mucin. Biochem J 1999, 338(Pt 2):325-333.

4. Khorrami AM, Choudhury A, Andrianifahanana M, Varshney GC, Bhattacharyya SN, Hollingsworth MA, Kaufman B, Batra SK: Purification and characterization of a human pancreatic adenocarcinoma mucin. J Biochem 2002, 131:21-29.

5. Gross MS, Guyonnet-Duperat V, Porchet N, Bernheim A, Aubert JP, Nguyen VC: Mucin 4 (MUC4) gene: regional assignment (3q29) and RFLP analysis. Ann Genet 1992, 35:21-26.

6. Hollingsworth MA, Swanson BJ: Mucins in cancer: protection and control of the cell surface. Nat Rev Cancer 2004, 4:45-60.

7. Chaturvedi P, Singh AP, Batra SK: Structure, evolution, and biology of the MUC4 mucin. FASEB J 2008, 22:966-981.

8. Andrianifahanana M, Moniaux N, Schmied BM, Ringel J, Friess $\mathrm{H}$, Hollingsworth MA, Buchler MW, Aubert JP, Batra SK: Mucin (MUC) gene expression in human pancreatic adenocarcinoma and chronic pancreatitis: a potential role of MUC4 as a tumor marker of diagnostic significance. Clin Cancer Res 2001, 7:4033-4040.

9. Jhala N, Jhala D, Vickers SM, Eltoum I, Batra SK, Manne U, Eloubeidi M, Jones JJ, Grizzle WE: Biomarkers in Diagnosis of pancreatic carcinoma in fine-needle aspirates. Am J Clin Pathol 2006, 126:572-579.

10. Zhu Y, Zhang JJ, Zhu R, Liang WB, Gao WT, Yu JB, Xu ZK, Miao Y: The increase in the expression and hypomethylation of MUC4 gene with the progression of pancreatic ductal adenocarcinoma. Med Oncol 2011, 28(Suppl 1):S175-S184

11. Saitou M, Goto M, Horinouchi M, Tamada S, Nagata K, Hamada T, Osako M, Takao S, Batra SK, Aikou T, Imai K, Yonezawa S: MUC4 expression is a novel prognostic factor in patients with invasive ductal carcinoma of the pancreas. J Clin Pathol 2005, 58:845-852.

12. Moniaux N, Escande F, Batra SK, Porchet N, Laine A, Aubert JP: Alternative splicing generates a family of putative secreted and membrane-associated MUC4 mucins. Eur J Biochem 2000, 267:4536-4544

13. Choudhury A, Moniaux N, Winpenny JP, Hollingsworth MA, Aubert JP, Batra SK: Human MUC4 mucin CDNA and its variants in pancreatic carcinoma. $J$ Biochem 2000, 128:233-243.
14. Choudhury A, Moniaux N, Ringel J, King J, Moore E, Aubert JP, Batra SK: Alternate splicing at the 3 '-end of the human pancreatic tumor-associated mucin MUC4 cDNA. Teratog Carcinog Mutagen 2001, 21:83-96.

15. Escande F, Lemaitre L, Moniaux N, Batra SK, Aubert JP, Buisine MP: Genomic organization of MUC4 mucin gene. Towards the characterization of splice variants. Eur J Biochem 2002, 269:3637-3644.

16. Bilimoria KY, Bentrem DJ, Ko CY, Ritchey J, Stewart AK, Winchester DP, Talamonti MS: Validation of the 6th edition AJCC Pancreatic Cancer Staging System: report from the National Cancer Database. Cancer 2007, 110:738-744.

17. Suzuki T, Higgins PJ, Crawford DR: Control selection for RNA quantitation. Biotechniques 2000, 29:332-337.

18. Livak KJ, Schmittgen TD: Analysis of relative gene expression data using real-time quantitative PCR and the 2(-Delta Delta C(T)) Method. Methods 2001, 25:402-408.

19. Ma C, Zhang J, Durrin LK, Lv J, Zhu D, Han X, Sun Y: The BCL2 major breakpoint region $(\mathrm{mbr})$ regulates gene expression. Oncogene 2007, 26:2649-2657

20. Huang S, Sinicrope FA: Sorafenib inhibits STAT3 activation to enhance TRAll-mediated apoptosis in human pancreatic cancer cells. Mol Cancer Ther 2010, 9:742-750.

21. Moniaux N, Chaturvedi P, Varshney GC, Meza JL, Rodriguez-Sierra JF, Aubert JP, Batra SK: Human MUC4 mucin induces ultra-structural changes and tumorigenicity in pancreatic cancer cells. Br J Cancer 2007, 97:345-357.

22. Yamada N, Nishida Y, Tsutsumida H, Goto M, Higashi M, Nomoto M, Yonezawa S: Promoter $\mathrm{CpG}$ methylation in cancer cells contributes to the regulation of MUC4. Br J Cancer 2009, 100:344-351.

23. Saldanha AJ: Java Treeview-extensible visualization of microarray data. Bioinformatics 2004, 20:3246-3248.

24. Kanehisa M, Araki M, Goto S, Hattori M, Hirakawa M, Itoh M, Katayama T, Kawashima S, Okuda S, Tokimatsu T, Yamanishi Y: KEGG for linking genomes to life and the environment. Nucleic Acids Res 2008, 36:D480-D484.

25. Zhang JJ, Zhu Y, Wu JL, Liang WB, Zhu R, Xu ZK, Du Q, Miao Y: Association of increased DNA methyltransferase expression with carcinogenesis and poor prognosis in pancreatic ductal adenocarcinoma. Clin Transl Oncol 2012, 14:116-124.

26. Hallemeier CL, Botros M, Corsini MM, Haddock MG, Gunderson LL, Miller RC: Preoperative CA 19-9 level is an important prognostic factor in patients with pancreatic adenocarcinoma treated with surgical resection and adjuvant concurrent chemoradiotherapy. Am J Clin Oncol 2011, 34:567-572.

27. Steg A, Amm HM, Novak Z, Frost AR, Johnson MR: Gli3 mediates cell survival and sensitivity to cyclopamine in pancreatic cancer. Cancer Biol Ther 2010, 10:893-902.

28. Kleeff J, Maruyama H, Ishiwata T, Sawhney H, Friess H, Buchler MW, Korc M: Bone morphogenetic protein 2 exerts diverse effects on cell growth in vitro and is expressed in human pancreatic cancer in vivo. Gastroenterology 1999, 116:1202-1216.

29. Wend P, Runke S, Wend K, Anchondo B, Yesayan M, Jardon M, Hardie N, Loddenkemper C, Ulasov I, Lesniak MS, Wolsky R, Bentolila LA, Grant SG, Elashoff D, Lehr S, Latimer JJ, Bose S, Sattar H, Krum SA, Miranda-Carboni GA: WNT10B/beta-catenin signalling induces HMGA2 and proliferation in metastatic triple-negative breast cancer. EMBO Mol Med 2013, 5:264-279.

30. Gales D, Clark C, Manne U, Samuel T: The Chemokine CXCL8 in carcinogenesis and drug response. ISRN Oncol 2013, 2013:859154.

31. Zhu Z, Kleeff J, Kayed H, Wang L, Korc M, Buchler MW, Friess H: Nerve growth factor and enhancement of proliferation, invasion, and tumorigenicity of pancreatic cancer cells. Mol Carcinog 2002, 35:138-147.

32. Saleem M, Qadir Ml, Perveen N, Ahmad B, Saleem U, Irshad T: Inhibitors of apoptotic proteins: new targets for anticancer therapy. Chem Biol Drug Des 2013, 82:243-251.

33. Hu X, Guo J, Zheng L, Li C, Zheng TM, Tanyi JL, Liang S, Benedetto C, Mitidieri M, Katsaros D, Zhao X, Zhang Y, Huang Q, Zhang L: The heterochronic microRNA let-7 inhibits cell motility by regulating the genes in the actin cytoskeleton pathway in breast cancer. Mol Cancer Res 2013, 11:240-250.

34. Matsuo Y, Ochi N, Sawai H, Yasuda A, Takahashi H, Funahashi H, Takeyama H, Tong Z, Guha S: CXCL8/IL-8 and CXCL12/SDF-1alpha co-operatively promote invasiveness and angiogenesis in pancreatic cancer. Int $J$ Cancer 2009, 124:853-861. 
35. Wente MN, Keane MP, Burdick MD, Friess H, Buchler MW, Ceyhan GO, Reber HA, Strieter RM, Hines OJ: Blockade of the chemokine receptor CXCR2 inhibits pancreatic cancer cell-induced angiogenesis. Cancer Lett 2006, 241:221-227.

36. Meyer BS, Rademann J: Extra- and intracellular imaging of human matrix metalloprotease 11 (hMMP-11) with a cell-penetrating FRET substrate. J Biol Chem 2012, 287:37857-37867.

37. Starr AE, Bellac CL, Dufour A, Goebeler V, Overall CM: Biochemical characterization and $\mathrm{N}$-terminomics analysis of leukolysin, the membrane-type 6 matrix metalloprotease (MMP25): chemokine and vimentin cleavages enhance cell migration and macrophage phagocytic activities. J Biol Chem 2012, 287:13382-13395.

38. Wan J, Chai H, Yu Z, Ge W, Kang N, Xia W, Che Y: HIF-1alpha effects on angiogenic potential in human small cell lung carcinoma. J Exp Clin Cancer Res 2011, 30:77.

39. Pfister C, Pfrommer H, Tatagiba MS, Roser F: Vascular endothelial growth factor signals through platelet-derived growth factor receptor beta in meningiomas in vitro. Br J Cancer 2012, 107:1702-1713.

40. Chaturvedi P, Singh AP, Moniaux N, Senapati S, Chakraborty S, Meza JL, Batra SK: MUC4 mucin potentiates pancreatic tumor cell proliferation, survival, and invasive properties and interferes with its interaction to extracellular matrix proteins. Mol Cancer Res 2007, 5:309-320.

41. Komatsu M, Carraway CA, Fregien NL, Carraway KL: Reversible disruption of cell-matrix and cell-cell interactions by overexpression of sialomucin complex. J Biol Chem 1997, 272:33245-33254.

42. Jepson S, Komatsu M, Haq B, Arango ME, Huang D, Carraway CA, Carraway KL: Muc4/sialomucin complex, the intramembrane ErbB2 ligand, induces specific phosphorylation of ErbB2 and enhances expression of p27(kip), but does not activate mitogen-activated kinase or protein kinaseB/Akt pathways. Oncogene 2002, 21:7524-7532.

43. Workman HC, Sweeney C, Carraway KL 3rd: The membrane mucin Muc4 inhibits apoptosis induced by multiple insults via ErbB2-dependent and ErbB2-independent mechanisms. Cancer Res 2009, 69:2845-2852.

44. Singh AP, Moniaux N, Chauhan SC, Meza JL, Batra SK: Inhibition of MUC4 expression suppresses pancreatic tumor cell growth and metastasis. Cancer Res 2004, 64:622-630.

45. Zhi X, Tao J, Xie K, Zhu Y, Li Z, Tang J, Wang W, Xu H, Zhang J, Xu Z MUC4-induced nuclear translocation of beta-catenin: a novel mechanism for growth, metastasis and angiogenesis in pancreatic cancer. Cancer Lett 2014, 346:104-113.

46. Tarca AL, Draghici S, Khatri P, Hassan SS, Mittal P, Kim JS, Kim CJ, Kusanovic JP, Romero R: A novel signaling pathway impact analysis. Bioinformatics 2009, 25:75-82.

47. Dhillon AS, Hagan S, Rath O, Kolch W: MAP kinase signalling pathways in cancer. Oncogene 2007, 26:3279-3290.

48. Li X, Chen J, Hu X, Huang Y, Li Z, Zhou L, Tian Z, Ma H, Wu Z, Chen M, Han Z, Peng Z, Zhao X, Liang C, Wang $Y$, Sun L, Chen J, Zhao J, Jiang B, Yang $H$, Gui $Y$, Cai $Z$, Zhang $X$ : Comparative mRNA and microRNA expression profiling of three genitourinary cancers reveals common hallmarks and cancer-specific molecular events. PLoS One 2011, 6:e22570.

49. Engstrom PG, Tommei D, Stricker SH, Ender C, Pollard SM, Bertone P: Digital transcriptome profiling of normal and glioblastoma-derived neural stem cells identifies genes associated with patient survival. Genome Med 2012, 4:76.

50. Hembruff SL, Cheng N: Chemokine signaling in cancer: Implications on the tumor microenvironment and therapeutic targeting. Cancer Ther 2009, 7:254-267

51. Damera G, Xia B, Sachdev GP: IL-4 induced MUC4 enhancement in respiratory epithelial cells in vitro is mediated through JAK-3 selective signaling. Respir Res 2006, 7:39.

52. Damera G, Xia B, Ancha HR, Sachdev GP: IL-9 modulated MUC4 gene and glycoprotein expression in airway epithelial cells. Biosci Rep 2006, 26:55-67.

53. Roberts KG, Morin RD, Zhang J, Hirst M, Zhao Y, Su X, Chen SC, Payne-Turner D, Churchman ML, Harvey RC, Chen X, Kasap C, Yan C, Becksfort J, Finney RP, Teachey DT, Maude SL, Tse K, Moore R, Jones S, Mungall K, Birol I, Edmonson MN, Hu Y, Buetow KE, Chen IM, Carroll WL, Wei L, Ma J, Kleppe M, et al: Genetic alterations activating kinase and cytokine receptor signaling in high-risk acute lymphoblastic leukemia. Cancer Cell 2012, 22:153-166.
54. Andrianifahanana M, Chauhan SC, Choudhury A, Moniaux N, Brand RE, Sasson AA, Pour PM, Batra SK: MUC4-expressing pancreatic adenocarcinomas show elevated levels of both T1 and T2 cytokines: potential pathobiologic implications. Am J Gastroentero/ 2006, 101:2319-2329.

55. Ikushima H, Miyazono K: TGFbeta signalling: a complex web in cancer progression. Nat Rev Cancer 2010, 10:415-424

56. Nagaraj NS, Datta PK: Targeting the transforming growth factor-beta signaling pathway in human cancer. Expert Opin Investig Drugs 2010, 19:77-91.

57. Derynck R, Akhurst RJ, Balmain A: TGF-beta signaling in tumor suppression and cancer progression. Nat Genet 2001, 29:117-129.

58. Jonckheere N, Perrais M, Mariette C, Batra SK, Aubert JP, Pigny P, Van Seuningen I: A role for human MUC4 mucin gene, the ErbB2 ligand, as a target of TGF-beta in pancreatic carcinogenesis. Oncogene 2004, 23:5729-5738.

\section{doi:10.1186/s12967-014-0309-8}

Cite this article as: Zhu et al:: Specific-detection of clinical samples, systematic functional investigations, and transcriptome analysis reveals that splice variant MUC4/Y contributes to the malignant progression of pancreatic cancer by triggering malignancy-related positive feedback loops signaling. Journal of Translational Medicine 2014 12:309.

\section{Submit your next manuscript to BioMed Central and take full advantage of:}

- Convenient online submission

- Thorough peer review

- No space constraints or color figure charges

- Immediate publication on acceptance

- Inclusion in PubMed, CAS, Scopus and Google Scholar

- Research which is freely available for redistribution

Submit your manuscript at www.biomedcentral.com/submit
C) Biomed Central 